\title{
Surrogate fuels for the simulation of diesel engine combustion of novel biofuels
}

International J of Engine Research 2015, Vol. I6(4) 53I-546 (C) IMechE 2014

Reprints and permissions: sagepub.co.uk/journalsPermissions.nav DOI: $10.1177 / 1468087414534565$ jer.sagepub.com (SAGE

\author{
Bruno Kerschgens', Liming Cai', Heinz Pitsch', Andreas Janssen², \\ Markus Jakob ${ }^{2}$ and Stefan Pischinger ${ }^{2}$
}

\begin{abstract}
Recently, several promising biomass-derived fuels for diesel engines have been identified, produced, and tested. Diesel engine experiments confirmed very low soot and low nitrogen oxide emissions. With regard to further improvements of the combustion system, it is desirable to complement the diesel engine experiments with numerical simulations. To date, this is hindered by the lack of suitable chemical reaction mechanisms for these novel fuels. Therefore, a surrogate approach is presented here and applied in computational fluid dynamics simulations. Combustion and pollutant formation is simulated using the representative interactive flamelet model. Ignition, combustion, and pollutant formation are described in a consistent manner by inclusion of detailed reaction chemistry. Different mixtures of $n$-heptane, toluene, ethanol, dimethylether, ethane, and phenol are employed to describe the combustion chemistry of the biofuels. The compositions of the surrogate fuels are compiled according to hydrogen/carbon ratio, oxygen content, cetane rating, and molecular properties of the experimental fuels. Spray, injection, and evaporation properties of the experimental fuels, as obtained from spray vessel experiments, are included in the computational fluid dynamics simulations. By systematic comparison of experimental and numerical results, the surrogate methodology is validated and an improved understanding of the limitations of the current surrogates is achieved. Thus, a methodology for the fast adoption of novel fuels for simulations is proposed that can be used regardless of the availability of specific chemical reaction mechanisms.
\end{abstract}

\section{Keywords}

Diesel engine combustion, biofuels, detailed chemistry, surrogate fuels, computational fluid dynamics

Date received: 22 April 2014; accepted: 7 April 2014

\section{Introduction}

The need of future societies for continuous mobility necessitates the search for alternatives for fossil energy sources. One attractive option is the production and use of fuels from biomass, as they have the potential to considerably reduce carbon dioxide $\left(\mathrm{CO}_{2}\right)$ emissions as well as pollutant emissions such as soot or nitrogen oxides $\left(\mathrm{NO}_{\mathrm{x}}\right)$. The holistic development of these fuels as a combination of biomass processing and combustion technology has proven to be a research area with a high need for interdisciplinary cooperation between natural and engineering sciences. In this context, the Cluster of Excellence "Tailor-Made Fuels from Biomass" (TMFB) at Rheinisch Westfälische Technische Hochschule Aachen (RWTH) Aachen University was established in 2007 as part of the Excellence Initiative by the German Research Foundation in order to develop new, biomass-based, synthetic fuels for mobile applications.

Several novel biofuels for diesel engine combustion were identified and produced in the TMFB framework. Compared to standard diesel fuel, these fuels have an increased oxygen content and typically lower cetane rating. Diesel engine experiments utilizing these fuels confirmed very low soot and $\mathrm{NO}_{\mathrm{x}}$ emissions. ${ }^{1-4}$ As a

\footnotetext{
'Institute for Combustion Technology (ITV), RWTH Aachen University, Templergraben 64, 52056 Aachen, Germany

${ }^{2}$ Institute for Combustion Engines (VKA), RWTH Aachen University, Schinkelstraße 8, 52062 Aachen, Germany

\section{Corresponding author:}

Bruno Kerschgens, Institute for Combustion Technology (ITV), RWTH Aachen University, Templergraben 64, 52056 Aachen, Germany.

Email: b.kerschgens@itv.rwth-aachen.de
} 
drawback, increased emissions of unburned hydrocarbons (HCs) and carbon monoxide (CO), especially in the low-load operating range, have been observed.

To further improve the combustion system and assess fuel effects and emission formation mechanisms in more detail, it is desirable to complement the diesel engine experiments with numerical simulations. Here, simulations are performed using the representative interactive flamelet (RIF) model. ${ }^{5,6}$ In many studies concerning the modeling of compression ignition in internal combustion engines, the RIF model has been applied successfully. A general review of the model and its applications can be found in Barths et al. ${ }^{7}$ Different engines were investigated, ranging from small displacement volumes (300 $\mathrm{cm}^{3} /$ cylinder) to marine diesel (4800 $\mathrm{cm}^{3} /$ cylinder) engines. ${ }^{5,8-12}$ By the use of detailed chemical reaction mechanisms, the RIF model inherently accounts for low- and high-temperature auto-ignition, heat release, and pollutant formation. However, despite the focused research on reaction chemistry within the TMFB group and elsewhere, ${ }^{13-20}$ chemical reaction mechanisms of novel biofuels are not readily available. New fuel classes containing numerous isomers with partly very different chemical properties have to be considered. While the use of automated methods might speed up the reaction scheme generation considerably, the development of accurate mechanisms is also based on the validation against time-consuming experimental measurements and will remain complex. Even if mechanisms are developed for the presently considered fuels, future development of detailed chemical kinetics might not be able to keep up with the number of newly proposed bio-derived fuel components. The surrogate approach presented in the following tries to bridge the time between the appearance of a promising fuel candidate and the time when a detailed reaction scheme for this fuel becomes available. This approach is exemplified for 2-methyltetrahydrofuran (2-MTHF), a cellulose-derived fuel with a furanic structure, and for a blend of $70 \% \quad 2-\mathrm{MTHF}$ and $30 \%$ di- $n$-butylether (DnBE) by liquid volume.

This article is arranged as follows: the first section describes the combustion modeling approach employed in the current investigation. After this, the engine test bench, the investigated operating points, and the corresponding numerical setup are presented. This includes the composition of the surrogate fuels, the chemical reaction mechanism, and a comparison of the proposed surrogate to experimentally determined ignition delay times of 2-MTHF. To validate the spray setup for the engine simulations, spray vessel experiments at diesel engine-like conditions are compared to simulations, confirming the correct representation of the spray. Section "Results and discussion" contains the comparison of the numerical simulations to the engine experiments, including heat release rates (HRRs) and pollutant emissions. This is complemented by detailed analysis of the differences in pollutant formation for the investigated fuels and load points. Finally, the conclusions and major findings from the study are summarized.

\section{Mathematical model}

\section{Computational fluid dynamics code}

The computational fluid dynamics (CFD) code used in this work is AC-FluX (formerly known as GMTEC), a flow solver based on the finite volume method ${ }^{21}$ that employs unstructured, mostly hexahedral meshes. AC-FluX solves the partial differential equations for continuity and momentum, an equation for the total enthalpy (including heat of formation), and two equations to account for the turbulence ( $\mathrm{k}-\varepsilon$ model). AC-FluX is documented by Khalighi et al. ${ }^{22}$ and Ewald et al. ${ }^{23}$

The liquid phase is modeled using the discrete droplet model (DDM), which describes the spray using a Monte Carlo method. Since the spray consists of a large number of droplets, only the behavior of a representative subset of all droplets (called parcels) is calculated in detail. The gas phase and the liquid phase are coupled through source terms in the governing equations for the gas phase. A detailed description of the spray modeling in AC-FluX can be found in Spiekermann et al. ${ }^{24}$

To approximate the physical properties of the experimental fuels, toluene has been used. For the experimental fuels, the database is quite incomplete while the most relevant properties of toluene such as molecular weight (MW), heat of vaporization, critical pressure, and critical temperature are very similar. This approach is in line with the general concept of this article to provide a way to quickly integrate novel fuels into reactive CFD simulations, regardless of the lack of detailed experimental data. The approximation is validated by comparison of CFD simulations using toluene to spray vessel experiments below (section "Spray chamber"). Concerning the 2-MTHF/DnBE blend, a single-component vaporization model is used and the fuel composition is assumed uniform in the liquid phase, which is consistent with the typical modeling approach for other complex fuels. For instance, diesel fuel contains hundreds of species with a wide range of boiling temperatures, but no separation of these components is usually observed in evaporating diesel sprays. In a recent study, Hottenbach et al. ${ }^{25}$ optically investigated a diesel-like spray of an iso-octane/ethanol mixture, where no separation of these components could be found.

\section{Laminar flamelet concept}

The laminar flamelet concept views a turbulent flame as an ensemble of flamelet structures attached to the instantaneous position of the flame surface, which itself 
is corrugated by the turbulent flow field. The assumption of combustion occurring in thin, locally onedimensional layers was introduced by Williams. ${ }^{26}$ Flamelet equations based on the mixture fraction as independent parameter and using a scalar dissipation rate to describe the turbulent mixing process were derived by Peters. ${ }^{27,28}$ Reviews on the flamelet concept can be found in Peters. ${ }^{6,27-29}$ An asymptotic analysis of the species transport equations yields the flamelet equations for the mass fraction $Y$ of species $j$ as

$$
\frac{\partial Y_{j}}{\partial t}-\frac{\chi}{2} \frac{\partial^{2} Y_{j}}{\partial Z^{2}}-\frac{\dot{\omega}_{j}}{\rho}=0
$$

where $\chi$ denotes the scalar dissipation rate, $\rho$ is the density, and $\dot{\omega}_{j}$ is the chemical source term for species $j$, which is typically evaluated using detailed chemistry calculations. In the derivation of equation (1), unity Lewis numbers and equal diffusivities for all species are applied. The underlying model assumption is that mixing and diffusion processes are dominated by the turbulent flow field. Numerous experimental observations supporting this can be found in the literature. A more detailed discussion on the importance of molecular effects can be found in Pitsch. ${ }^{30}$

\section{RIF model}

Of fundamental importance for the RIF model is the separated treatment of physical and chemical processes, which decouples time scales and spatial discretization. This allows for solving the chemistry, which is extremely nonlinear especially during ignition, with time steps much smaller than the CFD time steps. Additionally, the discretization of the flame structure in phase space is independent of the spatial discretization used in the CFD simulation, and the flame structure is accessible for detailed analysis.

In Figure 1, the schematic flow diagram shows the interaction of the CFD and the flamelet code. At every time step, the CFD code passes the scalar dissipation rate conditioned on stoichiometric mixture $\hat{\chi}_{s t}$ and the mean pressure $\hat{p}$ to the flamelet code. Based on this information, a presumed shape for the dissipation rate, and the given initial and boundary conditions, the flamelet code solves equation (1) in addition to an energy equation in similar form with time steps that may be much smaller. The solution yields species profiles for every species contained in the chemical reaction mechanism. The species profiles as function of mixture fraction are convoluted with a presumed probability density function (PDF) of mixture fraction, typically taken to be a $\beta-\mathrm{PDF}^{31}$ scaled by the mean and the variance of the mixture fraction in a particular cell, to yield the mean species mass fractions for each CFD cell. This yields the three-dimensional species distribution, heat release, and temperature. The scalar dissipation rate considers the effect of turbulence on the flame chemistry regarding mixing and flame stretch.

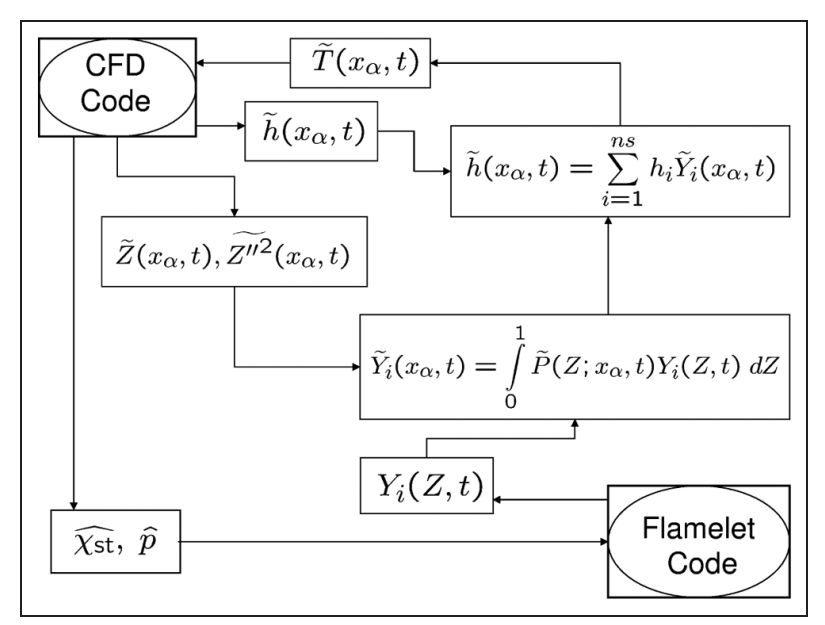

Figure I. Structure of the representative interactive flamelet concept.

CFD: computational fluid dynamics.

\section{Experimental and numerical setup}

\section{Diesel engine test bench}

The single-cylinder engine used for the diesel engine tests was operated at the Institute for Combustion Engines (VKA). It has a swept volume of $0.39 \mathrm{~L}$ and was designed for low emission levels and high fuel efficiency. A compression ratio of 15:1 was selected in order to keep the $\mathrm{NO}_{\mathrm{x}}$ emissions low in spite of the increased charge density, following typical Euro 6 development strategies. The combustion system reaches a specific output of $80 \mathrm{~kW} / \mathrm{L}$ at maximum peak firing pressures of 220 bar. A common rail system with a maximum fuel injection pressure of 2000 bar is used as injection system. To optimize the flow characteristics, one intake port was designed as a filling port and the second one as a classic swirl port. Creating charge movement was supported by seat swirl chamfers on both intake valves. The combustion chamber geometry was designed with a conventional recess shape, which was further optimized together with the nozzle geometry (eight-hole, $\mathrm{ks}=1.5$ ) in order to maximize air utilization. The low compression ratio of $15: 1$, early injection and high injection pressures, as well as improved exhaust gas recirculation (EGR) cooling make very low particulate emissions possible, and as a result, the research engine meets the Euro 6 standard. Table 1 shows a summary of the parameters of the test engine used. Additional information on the singlecylinder research engine can be found in earlier publications. $^{32-34}$

Four load points were selected, three of which are within the New European Driving Cycle (NEDC) range for an inertia weight class of $1590 \mathrm{~kg}$. The fourth load point is of interest for future downsizing concepts. Table 2 shows the respective calibration. Both fuels were analyzed with a single injection and at a constant center of combustion, which was chosen differently for the respective load points (see Table 2), whereby in each 
case the start of injection (SOI) was adjusted accordingly. The tolerance for the center of combustion is $\pm 0.1^{\circ}$ crank angle (CA). The constant $\mathrm{ISNO}_{\mathrm{x}}$ level was obtained by adjusting the EGR rate accordingly. The other calibration parameters such as intake manifold pressure, fuel injection pressure, and charge air temperature had been optimized in earlier studies for a realistic four-cylinder engine with a two-stage boosting device, all in compliance with the Euro 6 standard. ${ }^{35}$ Some details on the engine settings, along with the indicated efficiencies resulting from the above-described strategy, are given in Table 3.

\section{Spray chamber}

Shadowgraphic investigations of the fuel spray have been conducted in a high-pressure chamber, capable of

Table I. Single-cylinder engine configuration.

\begin{tabular}{ll}
\hline & Single-cylinder engine \\
\hline Benchmark & Euro 6 \\
Displacement $\left(\mathrm{cm}^{3}\right)$ & 390 \\
Stroke $(\mathrm{mm})$ & 88.3 \\
Bore diameter $(\mathrm{mm})$ & 75 \\
Compression ratio & 15 \\
Valves per cylinder & 4 \\
Maximum peak pressure (bar) & 220 \\
Fuel injection system specifications & Bosch Piezo Common \\
Maximum injection pressure (bar) & Rail System \\
HFR $\left(\mathrm{cm}^{3} / 30\right.$ s) & 2000 \\
Nozzle hole diameter $(\mu \mathrm{m})$ & 310 at 100 bar \\
Number of spray holes & 109 \\
Spray cone angle $\left({ }^{\circ}\right)$ & 8 \\
\hline
\end{tabular}

HFR: hydraulic flow rate. pressures up to 150 bar and temperatures up to 1000 $\mathrm{K}$. Details on the setup can be found in Jakob et al. ${ }^{36}$ The chamber is equipped with the same injection system as the diesel engine described above, ensuring comparability of the results. Density gradients as well as the shadow of the solid spray core are visualized, enabling the investigation of angle, penetration, distribution, and temporal development of the liquid and gaseous spray phase.

The sprays were investigated at two different ambient conditions, the lower at a temperature of $800 \mathrm{~K}$, back pressure of 50 bar, and rail pressure of 900 bar, corresponding to the engine conditions for load point 2 . The higher ambient conditions are at a temperature of $900 \mathrm{~K}$, back pressure of $100 \mathrm{bar}$, and rail pressure of 900 bar, corresponding to the engine conditions for load point 3. CFD calculations for these conditions have been performed and the parameters of the KelvinHelmholtz/Rayleigh-Taylor (KH/RT) breakup model were adjusted accordingly. The results for liquid and gaseous penetrations are compared to the measurements in Figure 2 for 2-MTHF and for the 2-MTHF/ DnBE blend in Figure 3. In all cases, good agreement is shown. Thus, the approximation of the physical spray properties by toluene is confirmed and the correct representation of the spray, which is of major importance for diesel engine simulations, is validated.

\section{Numerical setup}

Computations started from intake valve closure (IVC) at $-134.6^{\circ} \mathrm{CA}$ after top dead center (aTDC) and ended at exhaust valve opening (EVO) at $120^{\circ} \mathrm{CA}$ aTDC. The starting solution at IVC was initialized with pressure and temperature taken from the experiments. The internal EGR rate was assumed to be $5 \%$. The EGR

Table 2. Engine calibration.

\begin{tabular}{|c|c|c|c|c|}
\hline \multirow[t]{2}{*}{ Load point } & \multirow{2}{*}{$\begin{array}{l}\text { Center of combustion } \\
\left({ }^{\circ} \mathrm{CA} \text { after TDC) }\right.\end{array}$} & \multicolumn{3}{|c|}{ Pressures (bar absolute) } \\
\hline & & Rail & Boost & Exhaust manifold \\
\hline $\begin{array}{l}\text { I. } n=1500 \mathrm{~min}^{-1}, \text { IMEP }=4.3 \mathrm{bar} \\
\text { 2. } \mathrm{n}=1500 \mathrm{~min}^{-1}, \text { IMEP }=6.8 \mathrm{bar} \\
\text { 3. } \mathrm{n}=2280 \mathrm{~min}^{-1}, \text { IMEP }=9.4 \mathrm{bar} \\
\text { 4. } \mathrm{n}=2400 \mathrm{~min}^{-1}, \text { IMEP }=14.8 \mathrm{bar}\end{array}$ & $\begin{array}{l}6.6 \text { at } 0.2 \mathrm{~g} / \mathrm{kW} \mathrm{h} \mathrm{ISNO}{ }_{x} \\
5.8 \text { at } 0.2 \mathrm{~g} / \mathrm{kW} \mathrm{h} \mathrm{ISNO}{ }_{x} \\
9.2 \text { at } 0.6 \mathrm{~g} / \mathrm{kW} \mathrm{h} \mathrm{ISNO} \mathrm{ISO}_{x} \\
10.8 \text { at } 0.75 \mathrm{~g} / \mathrm{kW} \mathrm{h} \mathrm{ISNO}{ }_{x}\end{array}$ & $\begin{array}{r}720 \\
900 \\
1400 \\
1800\end{array}$ & $\begin{array}{l}1.07 \\
1.5 \\
2.29 \\
2.6\end{array}$ & $\begin{array}{l}1.13 \\
1.6 \\
2.39 \\
2.8\end{array}$ \\
\hline
\end{tabular}

CA: crank angle; TDC: top dead center; IMEP: indicated mean effective pressure.

Table 3. Engine setting details.

\begin{tabular}{|c|c|c|c|c|c|c|c|c|}
\hline \multirow[t]{2}{*}{ Load point } & \multicolumn{4}{|l|}{ 2-MTHF } & \multicolumn{4}{|c|}{$70 \% 2-\mathrm{MTHF}+30 \% \mathrm{DnBE}$} \\
\hline & EGR (\%) & Inlet $\mathrm{O}_{2}(\%)$ & $\mathrm{SOI}\left({ }^{\circ} \mathrm{CA}\right.$ aTDC) & $\eta_{i}(\%)$ & EGR (\%) & Inlet $\mathrm{O}_{2}(\%)$ & $\mathrm{SOI}\left({ }^{\circ} \mathrm{CA}\right.$ aTDC) & $\eta_{i}(\%)$ \\
\hline I & \multirow{2}{*}{\multicolumn{4}{|c|}{ No ignition obtained }} & 32.4 & 18.2 & -17.65 & 41.5 \\
\hline 2 & & & & & 49.5 & 14.3 & -13.46 & 42.7 \\
\hline 3 & 47.4 & 15.5 & -11 & 45.4 & 43.4 & 16.9 & -5.31 & 44.6 \\
\hline 4 & 39.8 & 15.5 & -6.6 & 44.8 & 36.8 & 16.4 & -5.9 & 45.0 \\
\hline
\end{tabular}

2-MTHF: 2-methyltetrahydrofuran; DnBE: di-n-butylether; EGR: exhaust gas recirculation; SOI: start of injection; CA: crank angle; aTDC: after top dead center. 


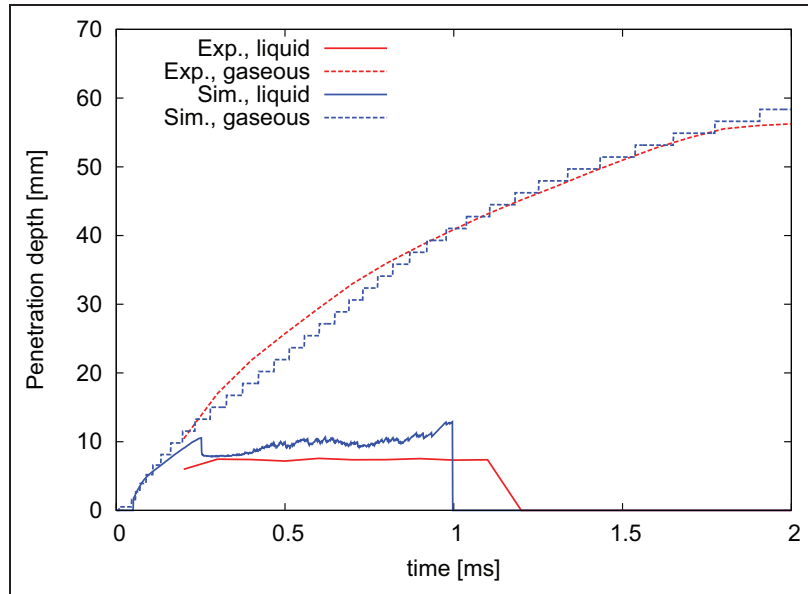

(a)

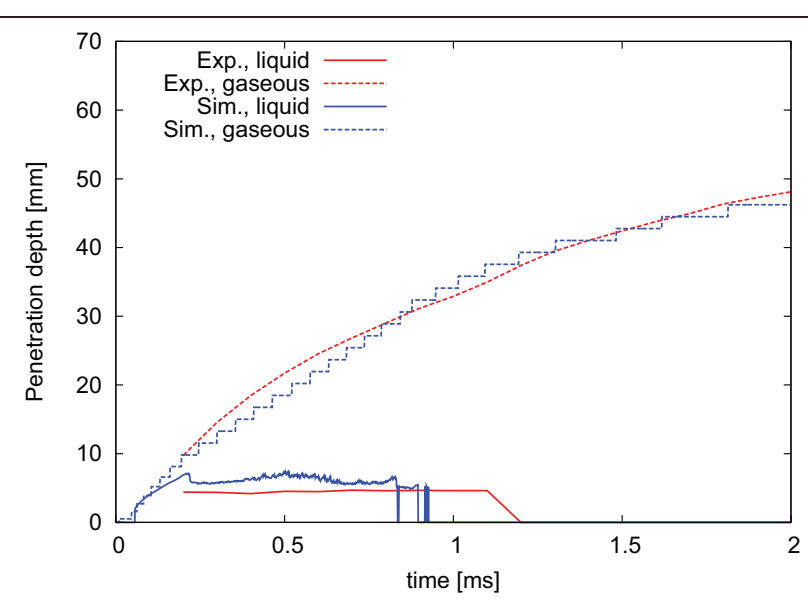

(b)

Figure 2. Comparison of liquid (solid lines) and gaseous (dashed lines) spray penetration from experiment (red) and simulation (blue) for 2-MTHF. Left part at 50 bar, $800 \mathrm{~K}$ ambient; right part at 100 bar, $900 \mathrm{~K}$ ambient.

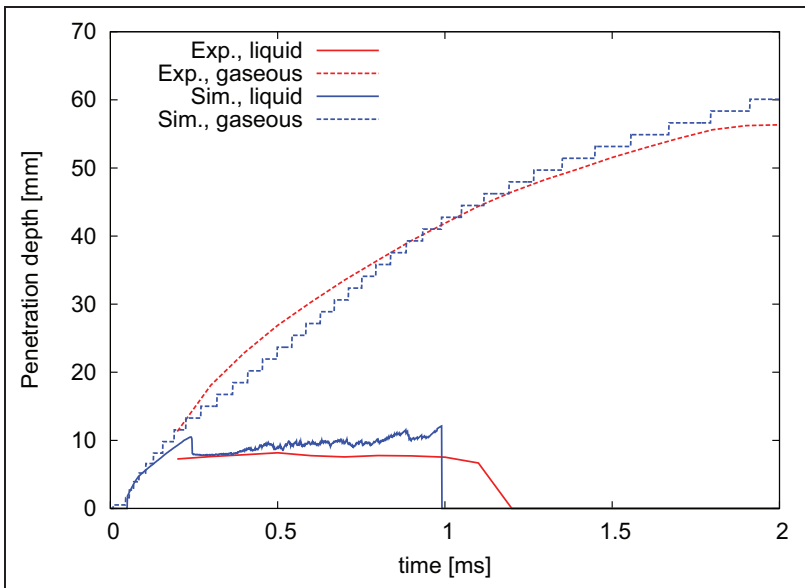

(a)

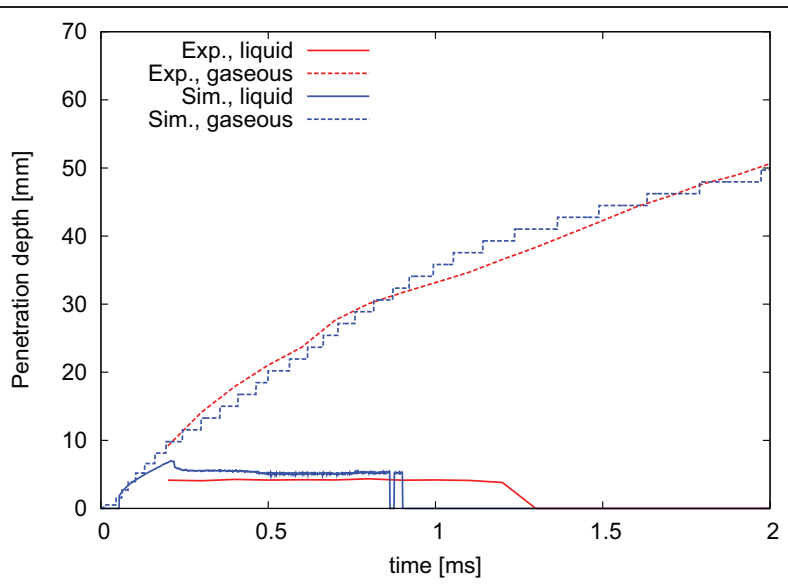

(b)

Figure 3. Comparison of liquid (solid lines) and gaseous (dashed lines) spray penetration from experiment (red) and simulation (blue) for the 2-MTHF/DnBE blend. Left part at 50 bar, $800 \mathrm{~K}$ ambient; right part at 100 bar, $900 \mathrm{~K}$ ambient.

composition regarding oxygen, $\mathrm{CO}, \mathrm{NO}_{\mathrm{x}}, \mathrm{CO}_{2}$, and water vapor content was initialized according to the experimental measurements. The velocity field was initialized with a swirl number of 1.159 , according to the experiments.

The simulation used a sector grid representing $1 / 8$ th of the combustion chamber, thereby taking advantage of the axial symmetry with respect to the placement of the nozzle holes. The mesh size was 40,224 cells at TDC. A sensitivity study revealed that this was a sufficient resolution for all cases. To account for the compression of the grid cells along the cylinder axis due to the piston movement, a cell layer removal technique was applied in the cylinder region throughout the simulations. Spray parameters were set according to the spray chamber simulations in the preceding subsection. The CPU time for a complete simulation is about $36 \mathrm{~h}$ on a single processor. The wall temperatures were set to $440 \mathrm{~K}$, based on experimental experience, and held constant during the simulations. The combustion chemistry is discretized on 101 grid points in $Z$ direction.

\section{Reaction chemistry}

Chemical reaction mechanism. A chemical reaction mechanism for a mixture of $n$-heptane, iso-octane, toluene, ethanol, dimethylether (DME), phenol, and ethane is used for the simulations. These compounds are often and widely used as surrogate compounds for petroleum fuels. Their mechanisms have been well studied and thus ensure the prediction accuracy in this study. DME is added to the palette to represent the oxygenated part of 2-MTHF. Also this component has been studied extensively and reliable chemical mechanisms are available.

A detailed chemical kinetic mechanism for DME was taken from Fischer et al. ${ }^{37}$ The mechanism consists of 79 species and 351 reversible reactions and was 
validated extensively over a wide range of temperatures, pressures, and equivalence ratios. ${ }^{37-39}$ Using a multistage reduction method by Pepiot-Desjardins and Pitsch, ${ }^{40}$ the detailed mechanism was reduced to a skeletal mechanism composed of 33 species and 64 forward and reverse reactions. The reduced mechanism was combined with a consistent chemical kinetic mechanism for $n$-heptane, iso-octane, toluene, and ethanol that consists of 631 reactions among 139 chemical species. A submechanism from Hewson and Bollig, ${ }^{41}$ which accounts for thermal, prompt, and nitrous oxide contributions to $\mathrm{NO}_{\mathrm{x}}$ formation and for $\mathrm{NO}_{\mathrm{x}}$ reburn by $\mathrm{HC}$ radicals and amines, is added, leading to a total number of 910 reactions and 170 chemical species. Rate conflicts detected during the combination were always resolved in favor of the better validated mechanism. ${ }^{42}$ The resulting mechanism accounts for low- and hightemperature auto-ignition, heat release, and pollutant formation. Soot emissions were very low in the experiments, with filter smoke numbers (FSNs) ranging from 0 to 0.09 . For the simulations, no soot model was used.

Surrogate approach. Surrogate fuels are mixtures of components with known reaction chemistry, compiled to match the behavior of a given fuel. Perhaps, the most widely known surrogate is the primary reference fuel, denoting a mixture of $n$-heptane and iso-octane that can be used to describe the knocking propensity of gasoline. Typically, surrogate fuels describe the reaction chemistry of fuels that are too complex in composition to be modeled directly, as is the case for essentially all fossil-based, liquid HC fuels. Examples for such surrogates can be found in Andrae et al., ${ }^{43}$ Dooley et al., ${ }^{44}$ Farrell et al., ${ }^{45}$ Krishnasamy et al., ${ }^{46}$ and Pitz et al. ${ }^{47}$ for diesel, gasoline, and jet fuels, respectively. While in these examples good results are obtained using surrogate fuels, there are obvious limitations for simple surrogates. For example, European premium gasoline has a research octane number $(\mathrm{RON})$ of 95 and a motor octane number (MON) of 85 . Octane numbers (ONs) are defined such that the fuel behaves like a mixture $\mathrm{ON}-\%$ iso-octane with $n$-heptane in a standardized engine test, with different boundary conditions for RON and MON. For diesel fuel, $n$-heptane is often used as surrogate because it has the same cetane rating. Evidently, aromaticity and hydrogen/carbon $(\mathrm{H} / \mathrm{C})$ ratio cannot be matched with such simple surrogates. However, despite this issue, these surrogates have often been shown to lead to satisfactory results.
Composition of surrogate fuel. In recent studies, the focus in the development of surrogates has shifted from representing the fuel composition as accurately as possible to a model-based matching of certain properties of the fuels. ${ }^{42,44,48}$ Properties matched in these studies are, for instance, $\mathrm{H} / \mathrm{C}$ molar ratio $(\mathrm{H} / \mathrm{C})$, derived cetane number (DCN), threshold sooting index (TSI), and average MW. These properties are often not interesting in their own right, but representative for important aspects of combustion behavior. For instance, $\mathrm{H} / \mathrm{C} / \mathrm{O}$ ratio is important for heat release, which determines flame temperature, which is important for NO formation. This means that not the fuel composition has to be matched by the surrogate, but only the part of the fuel molecular structure that is important for a certain property of interest. This implies that the palette of components chosen for the surrogate has to allow for independently matching the different important structural groups of the real fuel. If the chosen palette of surrogate components does not allow for matching the molecular structural groups of the real fuel, then adequate substitutions will have to be made. For example, soot formation is promoted by aromatics, but also by quaternary carbon, so either one can be used to increase the sooting tendency of a fuel. In that sense, matching the structural groups is very desirable, but not essential as long as the properties are matched.

The general methodology to define the surrogate composition is sketched in Figure 4. A set of properties that have to be matched is defined as a first step. These properties are as follows: cetane number, oxygen content, $\mathrm{H} / \mathrm{C}$ ratio, functional groups, and the existence of carbon-carbon double bonds in the molecules. Subsequently, a set of suitable surrogate components is chosen (see section "Chemical reaction mechanism"). The cetane number is chosen as a measure for the selfignitability of the fuels. Cetane numbers of the individual components are taken from the literature, while the other properties can be taken directly from the fuels' molecular structures. Oxygen content and $\mathrm{H} / \mathrm{C}$ ratio reflect adiabatic flame temperature and heat of combustion. In addition, the oxygen content of a fuel has a considerable impact on stoichiometry and soot formation. The cetane ratings of the surrogates are approximated by a linear interpolation of the cetane numbers of the individual components. Different properties of the components allow to fine tune the resulting surrogate properties (compare Table 4). Here, both $n$-heptane and DME have considerable low temperature

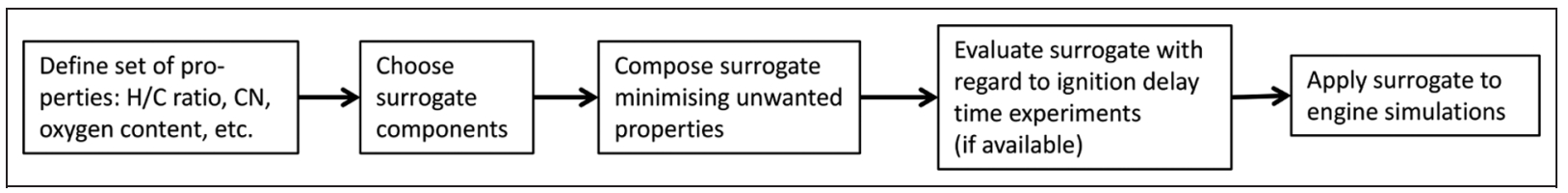

Figure 4. Flowchart showing the steps for the definition of the surrogate composition. $\mathrm{H} / \mathrm{C}$ : hydrogen/carbon; $\mathrm{CN}$ : cetane number. 
Table 4. Properties of experimental fuels and surrogate components.

\begin{tabular}{llllll}
\hline Fuel & Cetane number & Oxygen $(w t \%)$ & $\mathrm{H} / \mathrm{C}$ ratio (molar) & Functional group & $\mathrm{C}-\mathrm{C}$ double bonds \\
\hline 2-MTHF & 19.8 & 18.6 & 2.0 & $\mathrm{CH}_{3}$ & No \\
2-MTHF/DnBE blend & 36.1 & 16.1 & 2.1 & $\mathrm{CH}_{3}$, ether & No \\
n-Heptane & 52.5 & - & 2.29 & $\mathrm{CH}_{3}$ & No \\
DME & 56 & 34.8 & 2.5 & $\mathrm{CH}_{3}$, ether & No \\
Ethanol & 10 & 34.8 & 2.5 & $\mathrm{OH}$ & No \\
Toluene & 9 & - & 1.14 & $\mathrm{CH}_{3}$ & Yes \\
Ethane & 0 & - & 3 & $\mathrm{CH}_{3}$ & No \\
Phenol & 5 & 17.0 & 1.0 & $\mathrm{OH}$ & Yes \\
\hline
\end{tabular}

H/C: hydrogen/carbon; 2-MTHF: 2-methyltetrahydrofuran; DnBE: di-n-butylether; DME: dimethylether.

Table 5. Properties of experimental fuels and fuel surrogates.

\begin{tabular}{lllll}
\hline & $2-M T H F$ & Surrogate & $70 \%$ 2-MTHF + 30\% DnBE & Surrogate \\
\hline Compound formula (wt\%) & $\mathrm{C}_{5} \mathrm{H}_{10} \mathrm{O}$ & $\begin{array}{l}26 \% \text { n-Heptane } \\
\text { 8\% DME }\end{array}$ & $73.5 \% \mathrm{C}_{5} \mathrm{H}_{10} \mathrm{O}$ & $23.5 \%$ n-Heptane \\
& & $30 \%$ Ethanol & $26.5 \% \mathrm{C}_{8} \mathrm{H}_{18} \mathrm{O}$ & $33 \%$ DME \\
& & $6 \%$ Ethane & & $3.5 \%$ Ethanol \\
& & $30 \%$ Phenol & 2.1 & $30 \%$ Toluene \\
$\mathrm{H} / \mathrm{C}$ ratio & 2.0 & 2.1 & 16.2 & 2.1 \\
Oxygen content (wt\%) & 18.6 & 18.3 & 36.1 & 36.2 \\
Cetane number & 19.8 & 19.8 & & 36.1 \\
\hline
\end{tabular}

2-MTHF: 2-methyltetrahydrofuran; DnBE: di-n-butylether; DME: dimethylether; H/C: hydrogen/carbon.

reactivity, contain methyl $\left(\mathrm{CH}_{3}\right)$ groups, and no $\mathrm{C}-\mathrm{C}$ double bonds. DME and ethanol have a high oxygen content while their $\mathrm{H} / \mathrm{C}$ ratio is rather high. Ethanol has the additional alcohol $(\mathrm{OH})$ functional group. Ethane has no double bonds, low ignitability, and a methyl group, but high $\mathrm{H} / \mathrm{C}$ ratio. Phenol contains oxygen and has a low $\mathrm{H} / \mathrm{C}$ ratio. Toluene and phenol help to reduce the $\mathrm{H} / \mathrm{C}$ ratio of the mixture, but add $\mathrm{C}-\mathrm{C}$ double bonds.

For the 2-MTHF surrogate, DME, ethanol, and phenol are used to set the oxygen content. To keep the cetane number of the mixture in the desired range, the amount of DME has to be limited, despite its favorable properties regarding methyl group and $\mathrm{C}-\mathrm{C}$ bonds. Finally, $n$-heptane and a small amount of ethane are used to fine tune the low temperature reactivity of the surrogate mixture. For the 2-MTHF/DnBE blend surrogate, DME and ethanol are used to match the oxygen content. Here, a higher portion of DME can be used due to the higher cetane number of the experimental fuel. Also with regard to the ether functional group, DME fits the DnBE content of the blend very well. Toluene is used to keep $\mathrm{H} / \mathrm{C}$ ratio and cetane number at the desired level. A drawback of toluene is the $\mathrm{C}-\mathrm{C}$ double bonds in the molecule, while the methyl group corresponds to the methyl group of the experimental fuel. $n$-Heptane is also employed, adding low temperature reactivity.

First setting oxygen content, $\mathrm{H} / \mathrm{C}$ ratio, and cetane rating, and then minimizing unwanted additional properties (functional group and $\mathrm{C}-\mathrm{C}$ double bonds) yield the surrogate mixtures, as presented in Table 5. Due to the fact that the oxygen content and cetane rating of the 2-MTHF/DnBE blend are easier to match, the methodology works better for the blend surrogate. Here, more freedom is left to optimize the additional properties. However, for both surrogates, a rather high aromatic content, $\mathrm{OH}$ groups, and $\mathrm{C}-\mathrm{C}$ double bonds are present in contrast to the experimental fuels. Here, new surrogate components, better suited to the furanic structure of 2-MTHF, are desirable.

The surrogate approach renders combustion simulations of fuels with only roughly known reaction chemistry possible. Due to the use of verified chemical reaction schemes, kinetic information is retained in the approach, and ignition, combustion, and pollutant formation can be modeled with good accuracy, as will be shown in section "Results and discussion."

Ignition delay time validation for 2-MTHF surrogate. On the left part of Figure 5, experimental ignition delay time measurements from Brassat et al. ${ }^{13}$ and Heufer et al. ${ }^{16}$ for 2-MTHF at stoichiometric air-fuel mixture and 20 bar pressure are compared to zero-dimensional ignition delay time calculations for the individual surrogate components, using the FlameMaster Code. ${ }^{49}$ It is evident that none of the individual surrogate components matches the experimental behavior. In the right part of Figure 5, results from homogeneous reactor simulations for the 2-MTHF surrogate (see Table 5) are compared to the same experiments. 


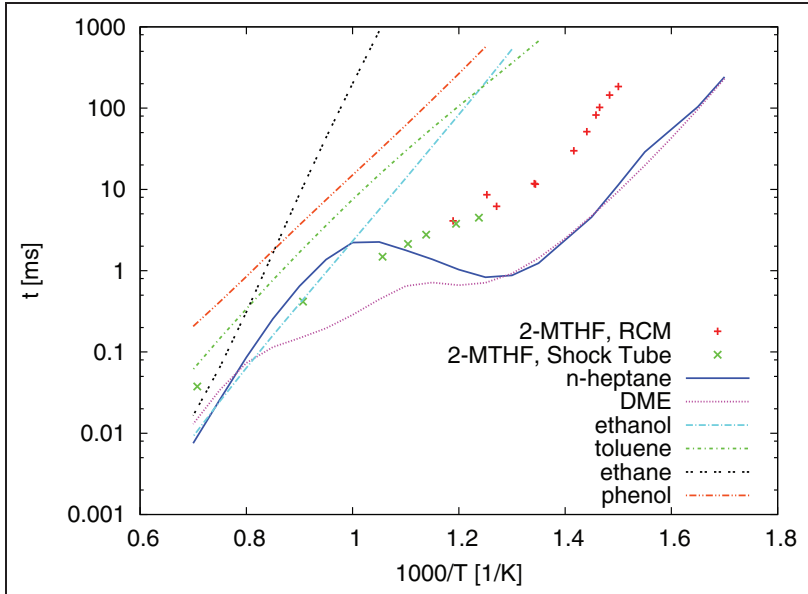

(a)

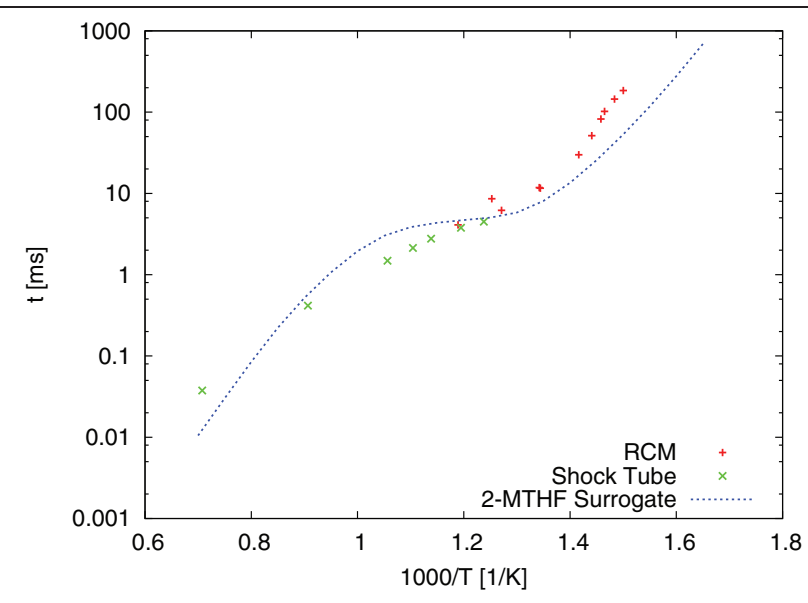

(b)

Figure 5. Ignition delay time over inverse of temperature at stoichiometric conditions and 20 bar. RCM experiments from Brassat et al. ${ }^{13}$ (red plus symbols) and shock tube experiments from Heufer et al. ${ }^{16}$ (green crosses) for 2-MTHF. Left part: ignition delay time for surrogate components compared to 2-MTHF measurements. Right part: results from 2-MTHF surrogate (blue, dotted line). 2-MTHF: 2-methyltetrahydrofuran; DME: dimethylether; RCM: rapid compression machine.

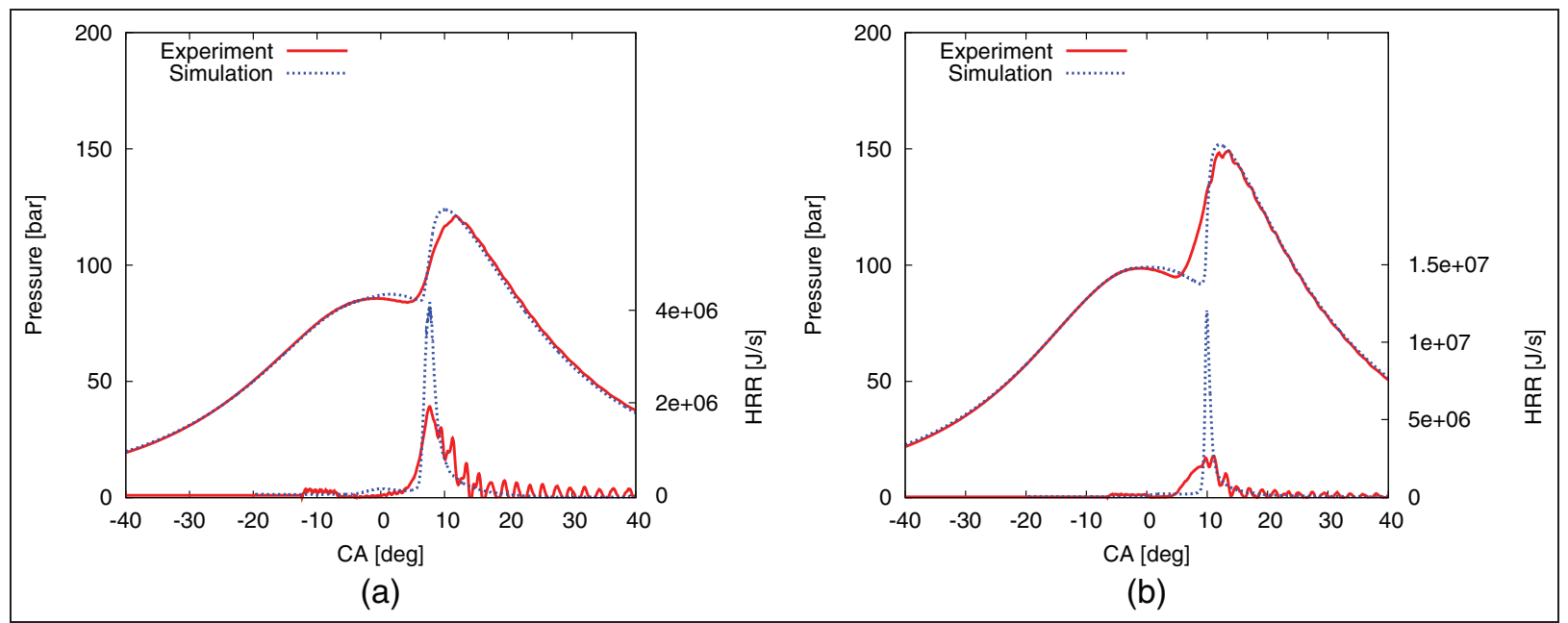

Figure 6. Pressure traces (left scale) and HRRs (right scale) for 2-MTHF. Load points 3 (left) and 4 (right) from engine experiment (red, solid line) and simulation (blue, dashed line).

CA: crank angle; HRR: heat release rate.

The calculated ignition delay times at high and intermediate temperatures (above $800 \mathrm{~K}$ ) match the experimental results quite well. For the lower temperatures, the ignition delay times calculated from the surrogate are shorter and the slope is flatter than the slope from the rapid compression machine (RCM) experiments. However, for ignition delay times greater than $50 \mathrm{~ms}$, heat losses become an increasingly relevant issue also for RCMs with creviced pistons, ${ }^{19}$ so the comparability of the RCM results at lower temperatures remains questionable. This example shows that by matching the specified fuel properties, the right balance of functional groups promoting chain branching and chain breaking was found, even if the surrogate composition does not exactly match the functional groups of the real fuel.
No ignition delay time measurements were available for the 2-MTHF/DnBE blend, limiting the assessment of the respective surrogate to the engine cases. Application of both surrogates to diesel engine simulations is discussed in the next section.

\section{Results and discussion}

\section{Comparison of experimental and numerical results}

Figure 6 compares the pressure traces and HRRs for 2-MTHF from the diesel engine experiments and the numerical results. As in the experiments and also the corresponding simulations, 2-MTHF did not ignite at the low load points 1 and 2, only the load points 3 and 


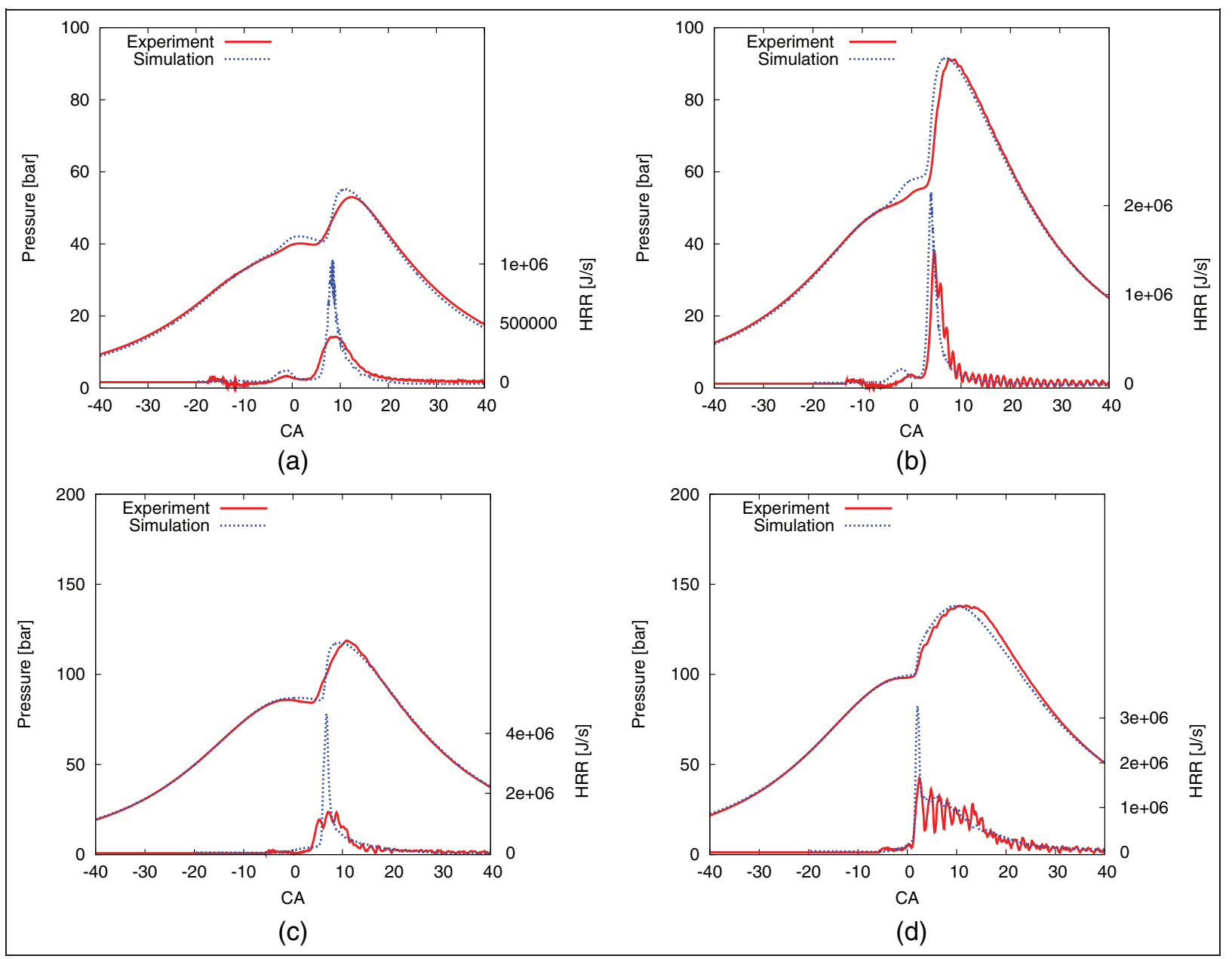

Figure 7. Pressure traces (left scale) and HRRs (right scale) for the 2-MTHF/DnBE blend. Load points I-4 (left to right, top to bottom) from engine experiment (red, solid line) and simulation (blue, dashed line).

CA: crank angle; HRR: heat release rate.

4 (see Table 3) are shown. For both cases, ignition timing and peak pressure from experiment and simulation match well. The HRR following the ignition is clearly overpredicted for both cases, producing a too steep pressure gradient, compared to the rather smooth experimental pressure rise. The first stage ignition and the corresponding low-temperature heat release are slightly overestimated. This corresponds to the too fast low-temperature chemistry, observed in Figure 5.

Figure 7 compares the pressure traces and HRRs for the 2-MTHF/DnBE blend from the diesel engine experiments and the numerical results for the corresponding surrogate (see Table 5). In the experiment, $30 \%$ DnBE (by liquid volume) was blended to the 2-MTHF in order to enable stable operation in the low load points 1 and 2. Simulations using the surrogate match the ignition timings of the experiments at all load points. The prediction quality for peak pressures and burn rates is satisfying. For the lower load points 1 and 2, low-temperature heat release is distinctly overpredicted and the subsequent pressure rise is too steep, yielding too high peak pressure for load point 1. For the higher load points 3 and 4, peak HRRs are overestimated, while ignition timing and peak pressures are matched with sufficient accuracy.

\section{Assessment of pollutant formation}

Figure 8 shows the emissions at EVO for load points 3 and 4 from operation with pure 2-MTHF from experiment and simulations. Regarding $\mathrm{CO}$ emissions, the simulations slightly overestimate the experimental results, while the trend is clearly reproduced. $\mathrm{NO}_{\mathrm{x}}$ emissions are distinctly underestimated by the surrogate, and emissions of unburned HCs are strongly overestimated. The general trend is captured for $\mathrm{NO}_{\mathrm{x}}$ as well as $\mathrm{HC}$ emissions.

Figure 9 depicts the emissions from operation with the 2-MTHF/DnBE blend and from the corresponding simulations. Again, $\mathrm{CO}$ emissions are slightly overpredicted, while the trend is reproduced across all load points. For $\mathrm{NO}_{\mathrm{x}}$, the trend is captured from load points 2 to 4 , with slightly underpredicted values. However, for load point 1 , simulated $\mathrm{NO}_{\mathrm{x}}$ emissions are too high, inverting the experimentally observed trend. The deficiency in $\mathrm{NO}_{\mathrm{x}}$ prediction may be attributed to the too 


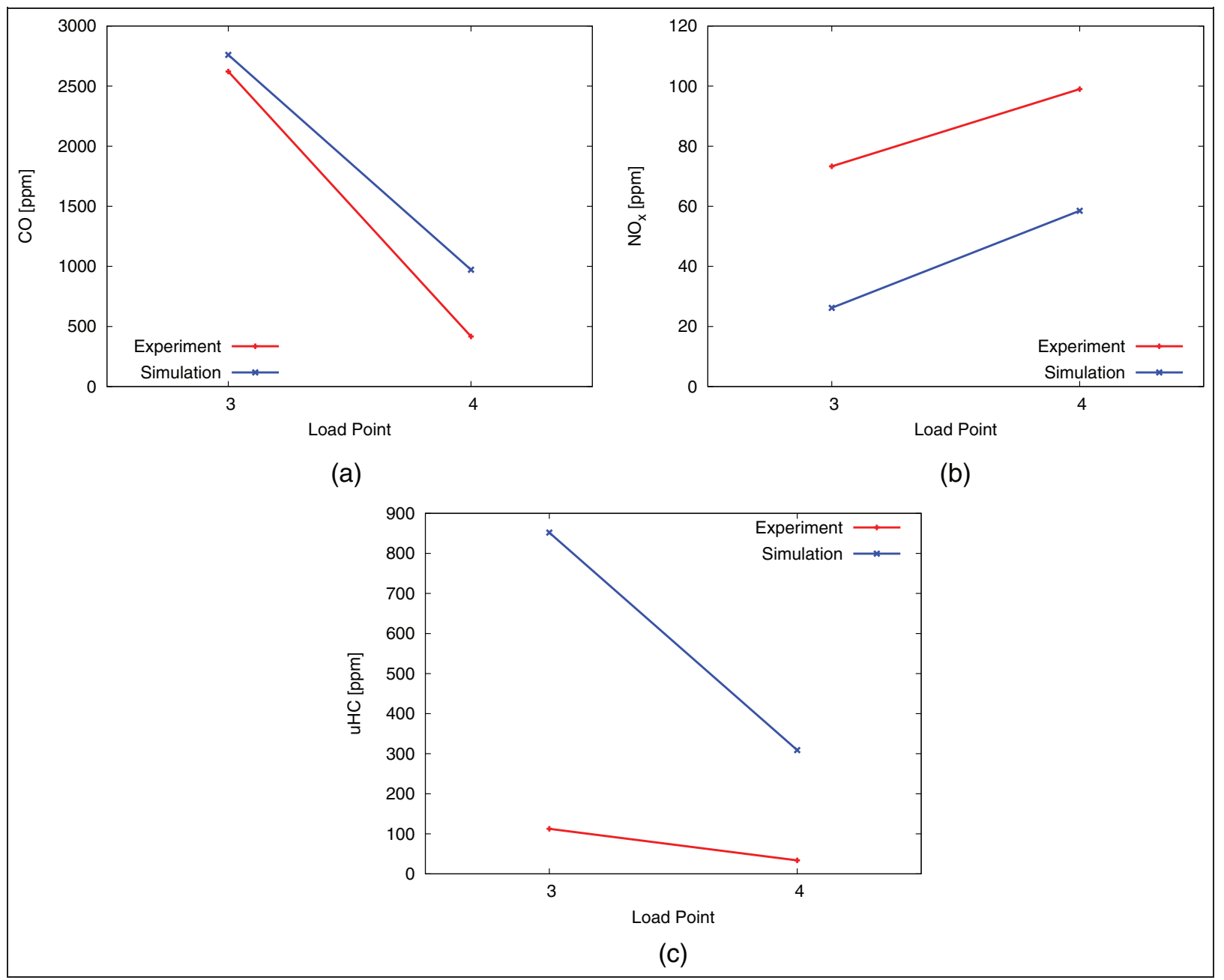

Figure 8. $\mathrm{CO}$ (left), $\mathrm{NO}_{x}$ (middle), and $\mathrm{HC}$ (right) emissions from experiment (red) and simulation (blue) for 2-MTHF. Load points 3 and 4.

$\mathrm{CO}$ : carbon monoxide; $\mathrm{NO}_{\times}$: nitrogen oxides; $\mathrm{HC}$ : hydrocarbon.

strong first stage heat release and overpredicted peak pressure for load point 1 (compare upper left of Figure 7), which leads to overpredicted peak temperatures and thus overestimated $\mathrm{NO}_{\mathrm{x}}$ emissions. $\mathrm{HC}$ emissions are overpredicted, while the general trend of decreasing $\mathrm{HC}$ emissions with increasing load is reproduced.

\section{Flame structure and fuel effects}

In the following, the flamelet solution is analyzed with regard to pollutant formation pathways and the differences between the two fuels and the respective load points. As described above, the chemistry is solved in flamelet space. In the flamelet, a mixture fraction value of $Z=0$ corresponds to pure oxidizer, while a value of $Z=1$ corresponds to pure fuel. The mixture fraction can be seen as a normalized equivalence ratio, ranging from 0 to 1 . The stoichiometric mixture fraction $Z_{s t}$ depends not only on the fuel but also on the oxygen concentration of the oxidizer and thus on the EGR rate. The individual values for $Z_{s t}$ are given in the captions of the respective figures below. The species mass fractions for each CFD cell are obtained by the integration of a $\beta-\mathrm{PDF},{ }^{31}$ scaled by the mean and the variance of the mixture fraction in the cell.

Figures 10-15 show the $\mathrm{CO}$ mass fraction, the $\mathrm{NO}_{\mathrm{x}}$ mass fraction (scaled by a factor of 100 to fit the axis), and the mass-weighted PDF of the mixture fraction for the whole CFD domain for the different fuels and load points. For better analysis of the graphs, only the range from $Z=0$ to $Z=0.1$ is shown, while computations included the whole range from 0 to 1 .

The left sides of Figures 10-15 show the flamelet profiles just after the main pressure rise (compare Figures 6 and 7), while the right sides show the profiles at EVO. In Figure 10, the flamelet solution profiles for the 2-MTHF surrogate at the third load point are presented. In the left part of Figure 10, the PDF shows a range of mixture fraction from 0 to 0.1 , indicating a stratified mixture, and a peak at $Z=0$, which indicates the presence of pure, unmixed oxidizer in the cylinder. As expected, the $\mathrm{CO}$ mass fraction sharply rises in the rich region (right of $Z_{s t}$ ). Another $\mathrm{CO}$ peak is observed at very lean conditions $(Z=0.025)$, indicating yet 


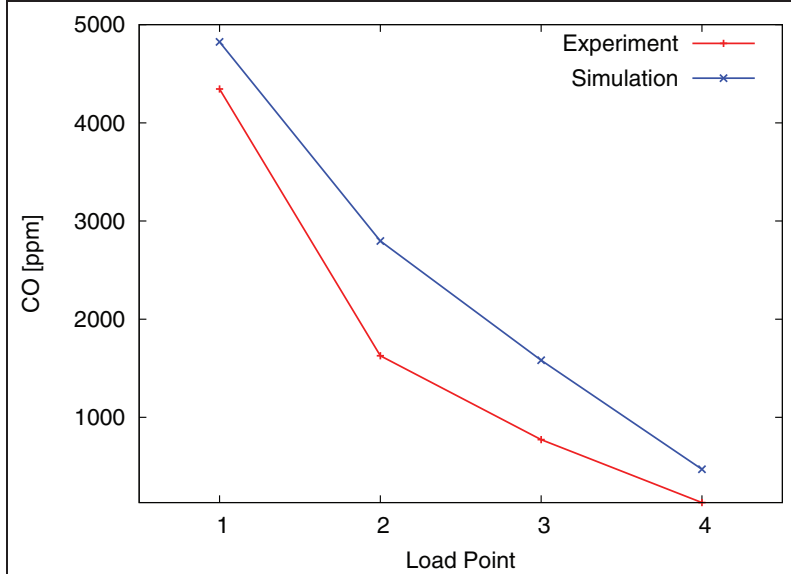

(a)

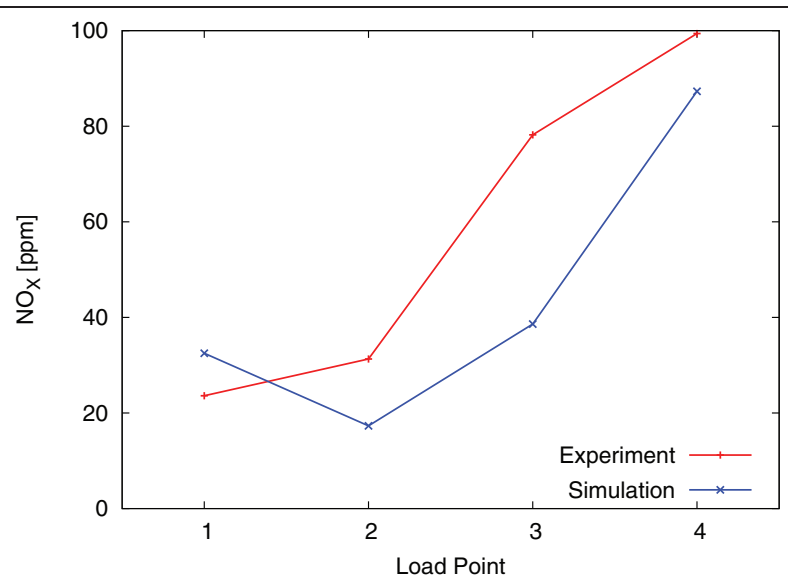

(b)

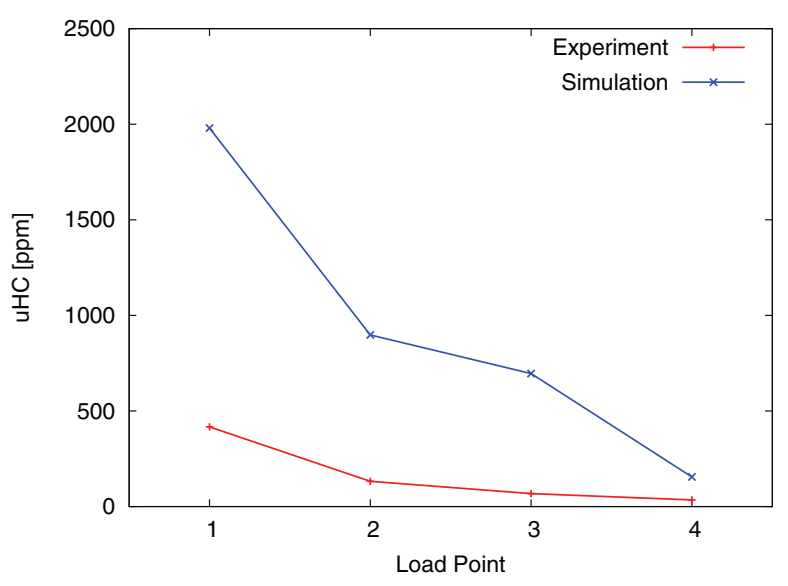

(c)

Figure 9. $\mathrm{CO}$ (left), $\mathrm{NO}_{\times}$(middle), and $\mathrm{HC}$ (right) emissions from experiment (red) and simulation (blue) for the 2-MTHF/DnBE blend. Load points $\mathrm{I}-4$.

$\mathrm{CO}$ : carbon monoxide; $\mathrm{NO}_{x}$ : nitrogen oxides; $\mathrm{HC}$ : hydrocarbon.

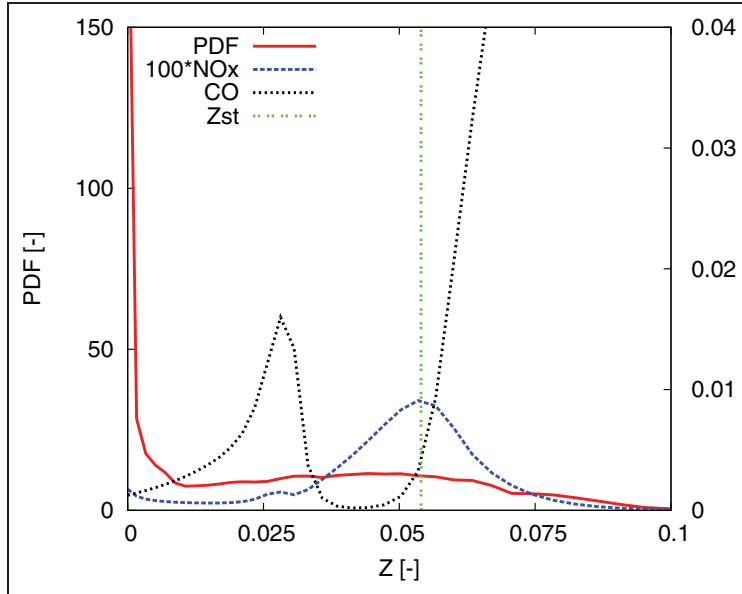

(a)

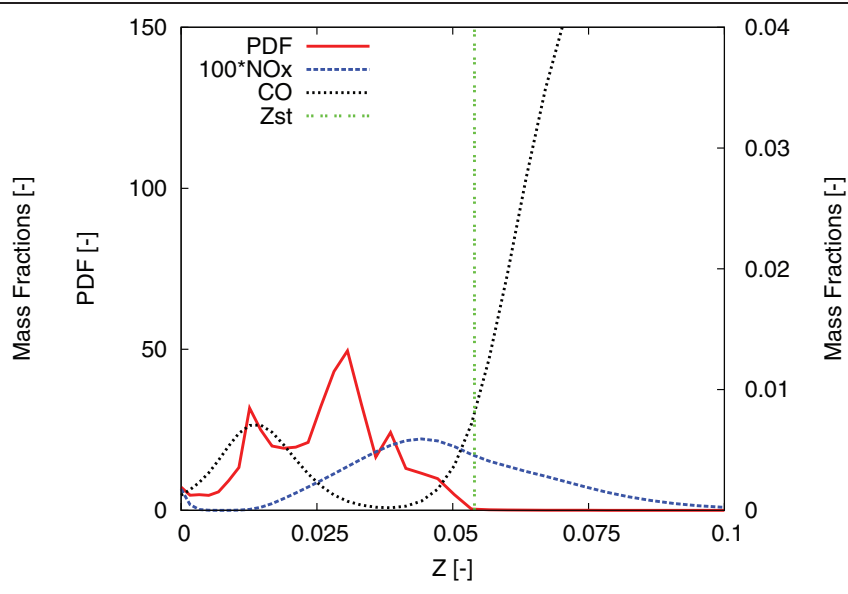

(b)

Figure 10. Flamelet solution profile for 2-MTHF for load point 3. PDF (red, solid line), NO mass fraction (blue, dashed line), and $\mathrm{CO}$ mass fraction (black, dotted line). Left side: at $10^{\circ} \mathrm{CA}$ after TDC; right side: at $120^{\circ} \mathrm{CA}$ after TDC. Stoichiometric mixture fraction (green, dashed-dotted line) is $Z_{s t}=0.054$.

PDF: probability density function; $\mathrm{NO}_{\times}$: nitrogen oxides; $\mathrm{CO}$ : carbon monoxide. 


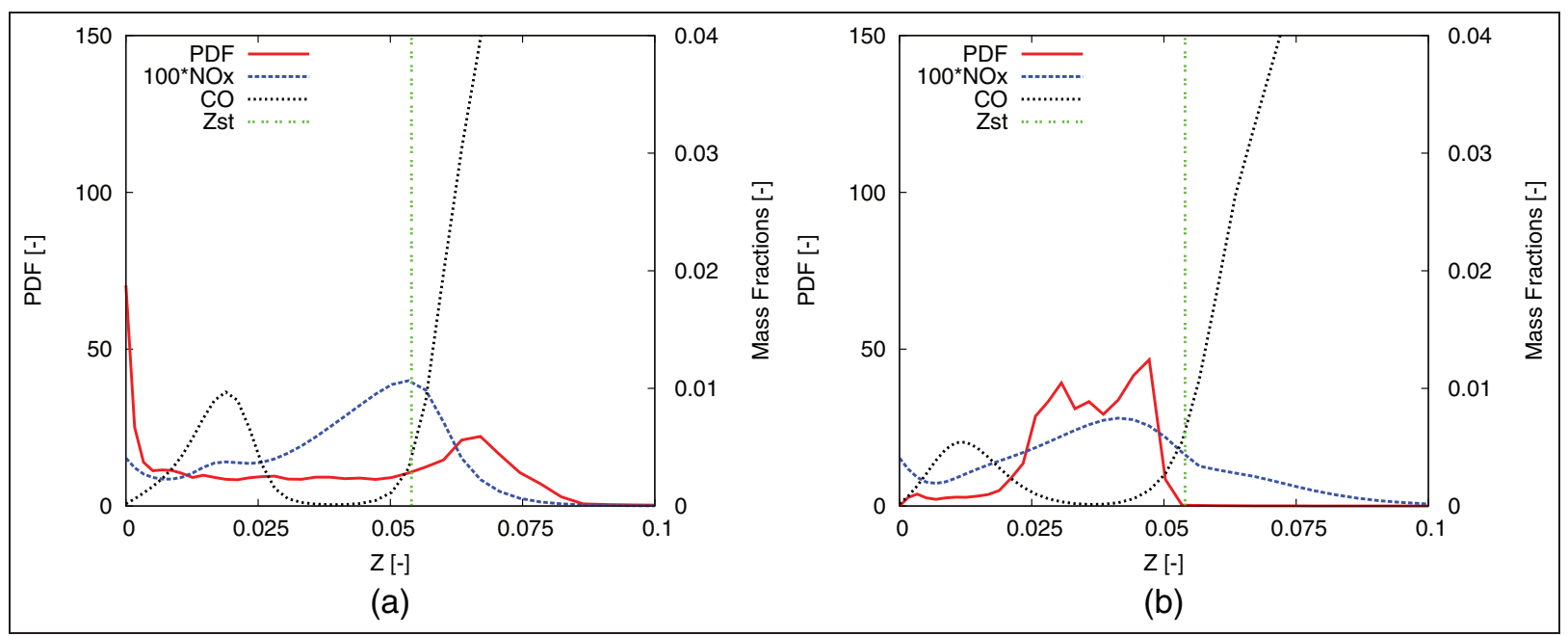

Figure II. Flamelet solution profile for 2-MTHF for load point 4. PDF (red, solid line), $\mathrm{NO}_{\mathrm{x}}$ mass fraction (blue, dashed line), and $\mathrm{CO}$ mass fraction (black, dotted line). Left side: at $14^{\circ} \mathrm{CA}$ after TDC; right side: at $120^{\circ} \mathrm{CA}$ after TDC. Stoichiometric mixture fraction (green, dashed-dotted line) is $Z_{s t}=0.054$.

PDF: probability density function; $\mathrm{NO}_{x}$ : nitrogen oxides; $\mathrm{CO}$ : carbon monoxide.

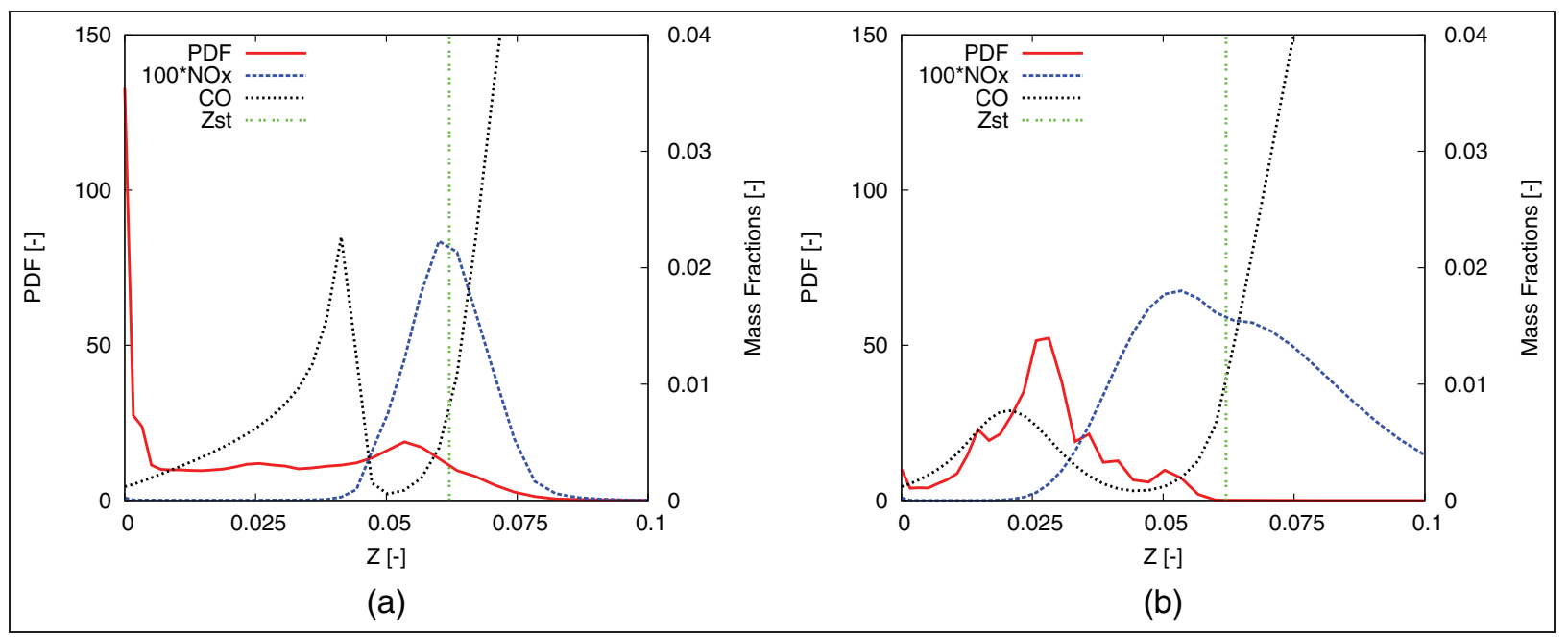

Figure 12. Flamelet solution profile for 2-MTHF/DnBE blend for load point I. PDF (red, solid line), $\mathrm{NO}_{x}$ mass fraction (blue, dashed line), and CO mass fraction (black, dotted line). Left side: at $10^{\circ} \mathrm{CA}$ after TDC; right side: at $120^{\circ} \mathrm{CA}$ after TDC. Stoichiometric mixture fraction (green, dashed-dotted line) is $Z_{s t}=0.062$.

PDF: probability density function; $\mathrm{NO}_{\mathrm{x}}$ : nitrogen oxides; $\mathrm{CO}$ : carbon monoxide.

unburned lean and presumably cold mixture. Between $Z \approx 0.03$ and $Z_{s t}$, the flamelet is fully ignited, and thus, only minor $\mathrm{CO}$ concentrations are left here. $\mathrm{The}^{\mathrm{NO}_{\mathrm{x}}}$ mass fraction is highest close to $Z_{s t}$, with a distinct decay toward the rich and the lean side. At the $Z=0$ boundary condition, small mass fractions of $\mathrm{CO}$ and $\mathrm{NO}_{\mathrm{x}}$ are present, reflecting the EGR in the oxidizer stream. At EVO (right part of Figure 10), the mixture has homogenized substantially, as indicated by the sharper, less distributed shape of the PDF. The $\mathrm{NO}_{\mathrm{x}}$ profile has flattened due to diffusive and reburn effects. The majority of the engine-out $\mathrm{CO}$ emissions originates from very lean mixtures, as indicated by the overlap of the $\mathrm{CO}$ profile and the PDF between $Z=0$ and $Z \approx 0.025$. The $\mathrm{CO}$ from close to stoichiometric mixture contributes only to a negligible fraction of the total $\mathrm{CO}$ emissions. These observations correspond to the results of Musculus et al. ${ }^{50}$ where it was shown experimentally that unburned $\mathrm{HC}$ emissions in a low-temperature combustion diesel engine originated from very lean regions, where the reaction rates are too low to complete combustion.

In Figure 11, the flamelet solution profiles for the 2-MTHF surrogate at the fourth load point are presented. The general evolution of the CO profile is quite similar to Figure 10. The shape of the PDF indicates more mixing prior to combustion and a more homogeneous mixture at EVO. The mean of the PDF at EVO is shifted to higher values of $Z$, yielding less overlap of PDF and CO profile and stronger overlap of PDF and 


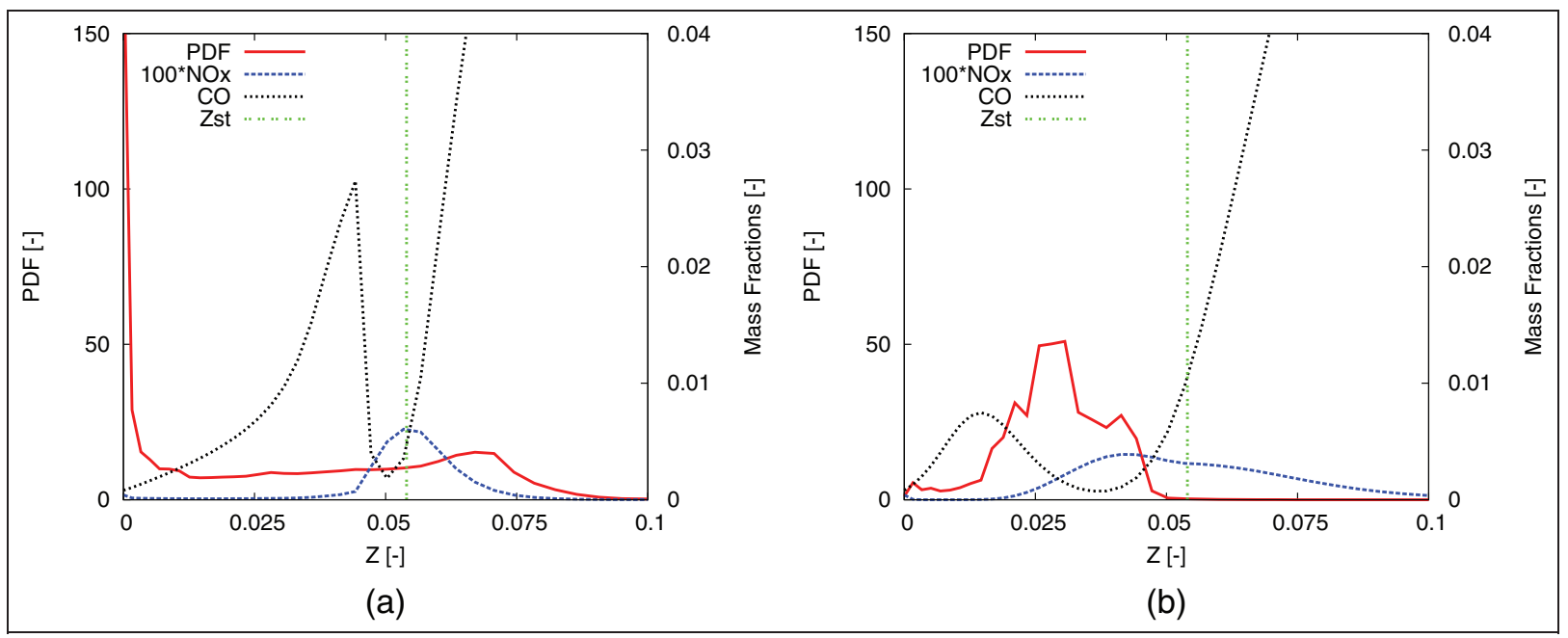

Figure 13. Flamelet solution profile for 2-MTHF/DnBE blend for load point 2. PDF (red, solid line), $\mathrm{NO}_{x}$ mass fraction (blue, dashed line), and $\mathrm{CO}$ mass fraction (black, dotted line). Left side: at $5^{\circ} \mathrm{CA}$ after TDC; right side: at $120^{\circ} \mathrm{CA}$ after TDC. Stoichiometric mixture fraction (green, dashed-dotted line) is $Z_{s t}=0.054$. PDF: probability density function; $\mathrm{NO}_{x}$ : nitrogen oxides; $\mathrm{CO}$ : carbon monoxide.

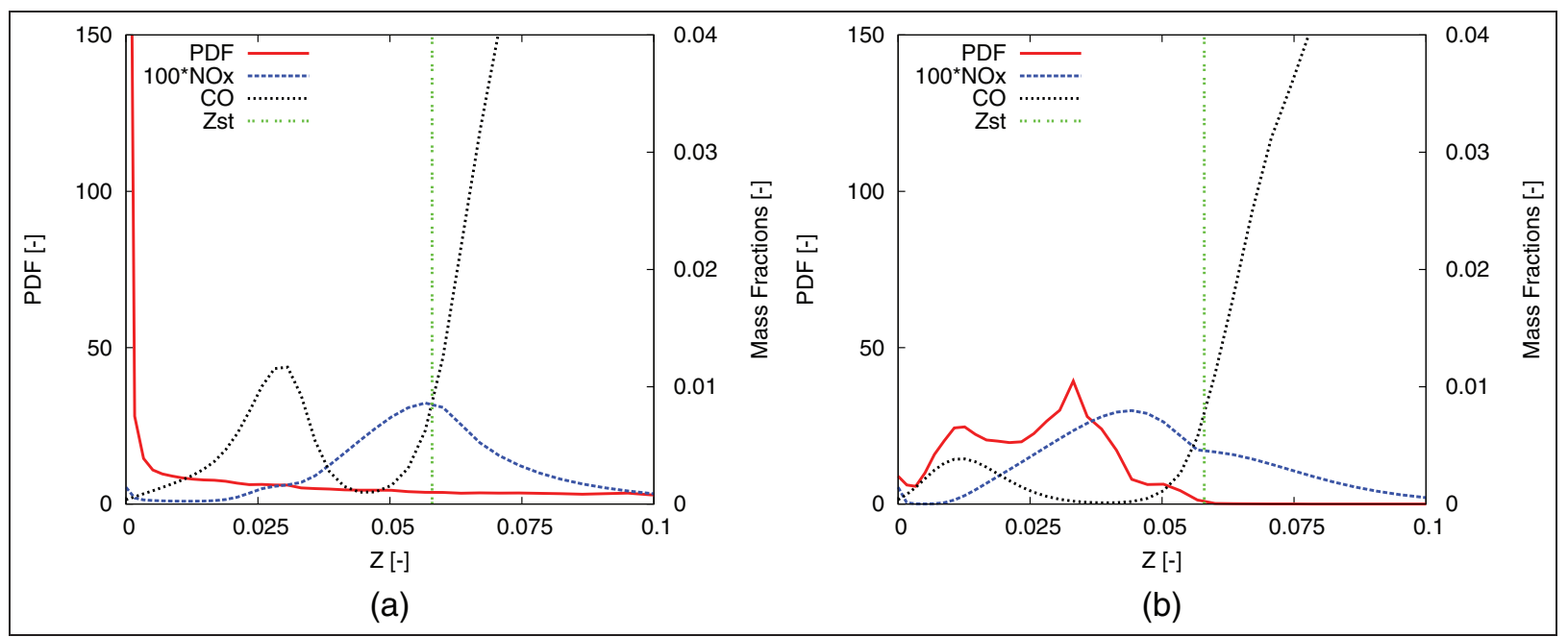

Figure 14. Flamelet solution profile for 2-MTHF/DnBE blend for load point 3. PDF (red, solid line), $\mathrm{NO}_{x}$ mass fraction (blue, dashed line), and $\mathrm{CO}$ mass fraction (black, dotted line). Left side: at $8^{\circ} \mathrm{CA}$ after TDC; right side: at $120^{\circ} \mathrm{CA}$ after TDC. Stoichiometric mixture fraction (green, dashed-dotted line) is $Z_{s t}=0.058$.

PDF: probability density function; $\mathrm{NO}_{x}$ : nitrogen oxides; $\mathrm{CO}$ : carbon monoxide.

$\mathrm{NO}_{\mathrm{x}}$ profile. This corresponds to the trends of lower $\mathrm{CO}$ and higher $\mathrm{NO}_{\mathrm{x}}$ emissions with increasing load, as observed in Figure 8. In addition, the CO mass fraction at very lean mixtures is slightly smaller while more $\mathrm{NO}_{\mathrm{x}}$ is present in the flamelet solution, which might be explained by the higher load and thus higher combustion temperatures.

In Figures 12-15, flamelet solution profiles for the 2-MTHF/DnBE blend for load points 1-4 are presented. For the first load point (Figure 12), high peaks of $\mathrm{CO}$ and $\mathrm{NO}_{\mathrm{x}}$ are present in the flamelet solution after ignition. At EVO, most of the $\mathrm{CO}$ is burned, but, similar to the cases before, a substantial amount of $\mathrm{CO}$ remains at the lean side. The PDF overlaps with this lean $\mathrm{CO}$ peak, leading to the high $\mathrm{CO}$ emissions observed for this load (compare left part of Figure 9). The rather high $\mathrm{NO}_{\mathrm{x}}$ mass fraction in the flamelet at EVO corresponds to the overestimated engine-out $\mathrm{NO}_{\mathrm{x}}$ emissions (compare right part of Figure 9). The significantly different $\mathrm{NO}_{\mathrm{x}}$ profiles from Figures 12 and 13 are attributed to the higher inlet oxygen concentration for load point 1 (compare Table 3) and also to the overestimated first-stage heat release and subsequently overpredicted peak pressure (compare upper left of Figure 7), which leads to overpredicted peak temperatures and thus overestimated $\mathrm{NO}_{\mathrm{x}}$ emissions. For the second load point (Figure 13), the CO profile evolves very similar to load point 1 . Due to the different means 


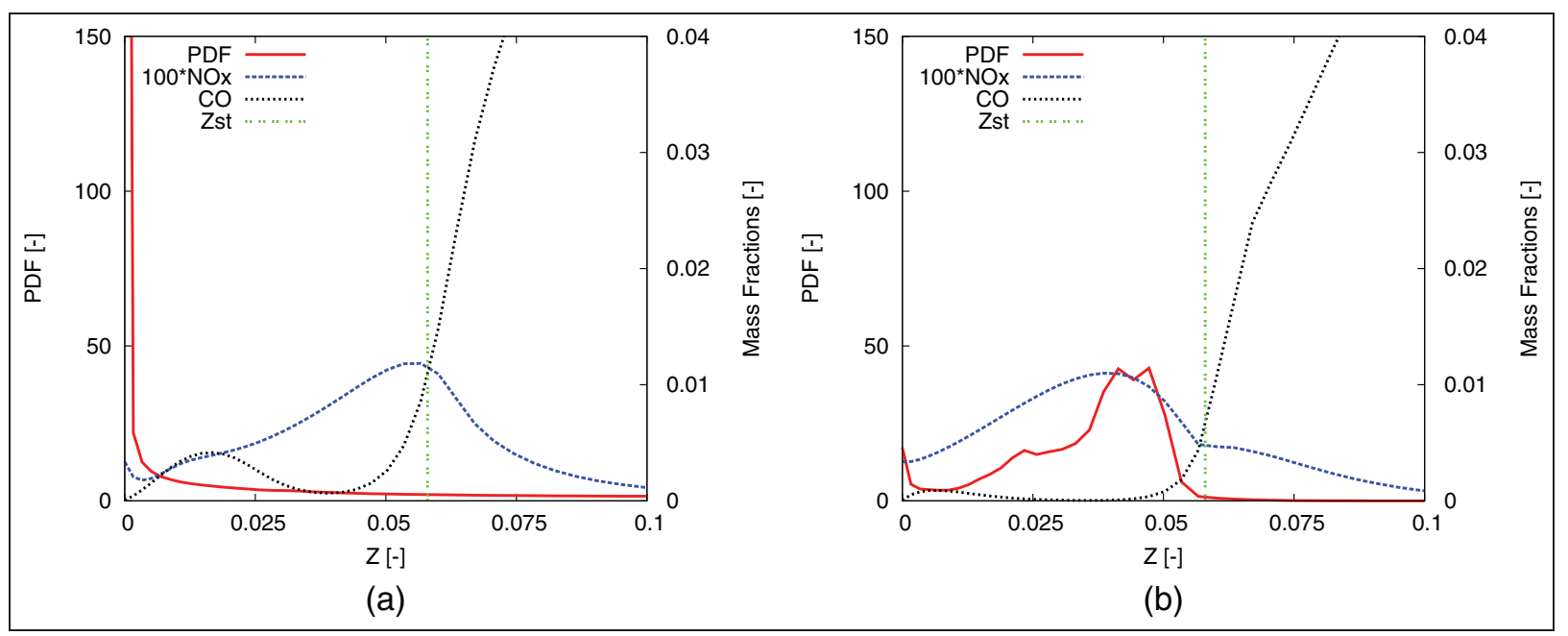

Figure 15. Flamelet solution profile for 2-MTHF/DnBE blend for load point 4. PDF (red, solid line), $\mathrm{NO}_{x}$ mass fraction (blue, dashed line), and $\mathrm{CO}$ mass fraction (black, dotted line). Left side: at $5^{\circ} \mathrm{CA}$ after TDC; right side: at $120^{\circ} \mathrm{CA}$ after TDC. Stoichiometric mixture fraction (green, dashed-dotted line) is $Z_{s t}=0.058$. PDF: probability density function; $\mathrm{NO}_{x}$ : nitrogen oxides; $\mathrm{CO}$ : carbon monoxide.

of the PDF at EVO (right part of Figure 13) and the resulting smaller overlap of $\mathrm{CO}$ profile and $\mathrm{PDF}$, the engine-out $\mathrm{CO}$ emissions are distinctly lower, compared to load point 1 . The $\mathrm{NO}_{\mathrm{x}}$ mass fraction in the flamelet is distinctly lower, yielding lower engine-out $\mathrm{NO}_{\mathrm{x}}$ emissions despite the stronger overlap of $\mathrm{NO}_{\mathrm{x}}$ profile and PDF.

In the context of Figures 14 and 15, especially the comparison to Figures 10 and 11 is of interest, as it shows the influence of the fuel on flame structure and emissions. In Figure 14, the PDF indicates less premixing prior to combustion than for the same load point with pure 2-MTHF (Figure 10). Due to stronger mixing during combustion, less $\mathrm{CO}$ from very lean regions is present at EVO in Figure 10. This leads to distinctly lowered engine-out emissions despite the similar PDF. The $\mathrm{NO}_{\mathrm{x}}$ mass fraction is slightly higher, probably due to the higher inlet oxygen concentration (see Table 3). In Figure 15, the PDF again indicates less premixing prior to combustion than for the same load point with pure 2-MTHF (Figure 11). The lowered CO emissions can be attributed to more mixing during and after combustion, almost completely eliminating the lean $\mathrm{CO}$ at EVO. Again, the $\mathrm{NO}_{\mathrm{x}}$ emissions are slightly higher.

In summary, the flamelet solution profiles indicate a substantial contribution of very lean regions to the $\mathrm{CO}$ emissions for all load points. For the 2-MTHF/DnBE blend, the mixture is less homogeneous at ignition, which leads to less overleaning and thus lower $\mathrm{CO}$ emissions than for operation with pure 2-MTHF. This corresponds to the difference in the cetane rating of the fuels (see Table 5). Differences in $\mathrm{NO}_{\mathrm{x}}$ emissions are attributed mainly to load and inlet oxygen concentration. However, due to the low sooting propensity of the experimental fuels, high EGR rates can be employed, keeping $\mathrm{NO}_{\mathrm{x}}$ emissions within Euro 6 regulation limits. $^{1-4}$

\section{Conclusion}

A surrogate approach to describe the combustion chemistry of novel biofuels in a diesel engine has been described and tested. The surrogate fuels have been compiled according to cetane number, oxygen content, $\mathrm{H} / \mathrm{C}$ ratio, and molecular properties of the biofuels. Ignition delay time calculations and diesel engine simulations, both using detailed reaction chemistry of a surrogate fuel, have been compared to the respective experiments for 2MTHF. The ignition delay time calculations confirmed the applicability of the surrogate approach. The assessment of the surrogate for a 2-MTHF/DnBE blend was limited to engine simulations, as no ignition delay time measurements were available.

For the engine simulations, good results regarding pressure traces and pollutant emissions were obtained. HRRs, however, were distinctly overestimated by the surrogates, showing the limitations of the approach. Nevertheless, the comparison to diesel engine experiments confirmed the proposed approach and the methodology to define the surrogate composition and allowed for insight into the pollutant formation processes in the engine. The increased cetane rating of the blended fuel proved to be beneficial in terms of $\mathrm{CO}$ emissions, minimizing over-leaned, noncombustible mixture.

\section{Declaration of conflicting interest}

The authors declared no potential conflicts of interest with respect to the research, authorship, and/or publication of this article.

\section{Funding}

This work has been performed within the Cluster of Excellence "Tailor-Made Fuels from Biomass," which is funded by the Excellence Initiative of the German 
federal and state governments to promote science and research at German universities.

\section{References}

1. Janssen A, Muether M, Pischinger S, Kolbeck A, Lamping $M$ and Koerfer T. Tailor-made fuels for future advanced diesel combustion engines. SAE paper 2009-011811, 2009.

2. Janssen A, Muether M, Pischinger S, Kolbeck A and Lamping M. Tailor-made fuels: the potential of oxygen content in fuels for advanced diesel combustion systems. SAE paper 2009-01-2765, 2009.

3. Janssen A, Muether M and Pischinger S. Potential of cellulose-derived biofuels for soot free diesel combustion. SAE Int J Fuels Lubr 2010; 3(1): 70-84.

4. Janssen A, Jakob M, Muether M, Pischinger S, Klankermayer $\mathbf{J}$ and Leitner $\mathrm{W}$. Tailor-made fuels from biomass - potential of biogenic fuels for reducing emissions. MTZ: Mot Z 2010; 71: 922-928.

5. Barths H, Pitsch H and Peters N. 3-D simulation of DI diesel combustion and pollutant formation using a twocomponent reference fuel. Oil Gas Sci Technol 1999; 54: 233-244.

6. Peters N. Laminar flamelet concepts in turbulent combustion. Symp Combust Proc 1986; 21: 1231-1250.

7. Barths H, Hasse $\mathrm{C}$ and Peters N. Computational fluid dynamics modelling of non-premixed combustion in direct injection diesel engines. Int $J$ Engine Res 2000; 1: 249-267.

8. Barths H, Hasse C, Bikas G and Peters N. Simulation of combustion in DI diesel engines using an Eulerian particle flamelet model. P Combust Inst 2000; 28: 1161-1168.

9. Hasse C, Barths H and Peters N. Modeling the effect of split injections in diesel engines using representative interactive flamelets. SAE paper 1999-01-3547, 1999.

10. Hergart CA, Barths $\mathrm{H}$ and Peters N. Modeling the combustion in a small-bore diesel engine using a method based on representative interactive flamelets. SAE paper 1999-01-3550, 1999.

11. Pitsch H, Barths $\mathrm{H}$ and Peters N. Three-dimensional modeling of $\mathrm{NO}_{\mathrm{x}}$ and soot formation in DI-diesel engines using detailed chemistry based on the interactive flamelet approach. SAE paper 962057, 1996.

12. Weber J, Peters N, Diwakar R, Siewert RM and Lippert A. Simulation of the low-temperature combustion in a heavy duty diesel engine. SAE paper 2007-01-0904, 2007.

13. Brassat A, Thewes M, Muether M, Pischinger S, Lee C, Fernandes RX, et al. Analysis of the effects of certain alcohol and furan-based biofuels on controlled auto ignition. SAE paper 2012-01-1135, 2012.

14. Cai L, Sudholt A, Lee DJ, Egolfopoulos FN, Pitsch H, Westbrook CK, et al. Chemical kinetic study of a novel lignocellulosic biofuel: di-n-butyl ether oxidation in a laminar flow reactor and flames. Combust Flame 2014; 161(3): 798-809.

15. Heufer KA, Fernandes RX, Olivier H, Beeckmann J, Röhl $\mathrm{O}$ and Peters N. Shock tube investigations of ignition delays of n-butanol at elevated pressures between $770 \mathrm{~K}$ and $1250 \mathrm{~K}$. P Combust Inst 2010; 33: 359-366.

16. Heufer KA, Olivier H, Medvedev SP and Khomik SV. Optical investigation of shock induced ignition of different biofuels. In: Proceedings of the 23rd ICDERS, University of California, Irvine, CA, 24-29 July 2011. USA:
Mechanical and Aerospace Engineering Department, University of California.

17. Vranckx S, Heufer KA, Lee C, Olivier H, Schill L, Kopp WA, et al. Role of peroxy chemistry in the high-pressure ignition of n-butanol - experiments and detailed kinetic modelling. Combust Flame 2011; 158: 1444-1455.

18. Vranckx S, Lee C and Fernandes RX. Auto-ignition kinetics of biomass derived alternative fuels for advanced combustion. SAE paper 2011-01-1780, 2011.

19. Vranckx S, Beeckmann J, Kopp WA, Lee C, Cai L, Chakravarty $\mathrm{HK}$, et al. An experimental and kinetic modelling study of n-butyl formate combustion. Combust Flame 2013; 160(12): 2680-2692.

20. Westbrook C. Biofuels combustion. Annu Rev Phys Chem 2013; 64: 201-219.

21. Ferziger JH and Perić M. Computational methods for fluid dynamics. Berlin: Springer, 2002.

22. Khalighi B, El Thary SH, Haworth DC and Huebler MS. Computation and measurement of flow and combustion in a four-valve engine with intake variations. SAE paper 950287, 1995.

23. Ewald J, Freikamp F, Paczko G, Weber J, Haworth DC and Peters N. GMTEC: GMTEC developer's manual. Aachen: Advanced Combustion GmbH, 2003.

24. Spiekermann P, Jerzembeck S, Felsch C, Vogel S, Gauding $\mathrm{M}$ and Peters N. Experimental data and numerical simulation of common-rail ethanol sprays at diesel engine-like conditions. Atomization Spray 2009; 19: 357 386.

25. Hottenbach P, Brands $\mathrm{T}$ and Grünefeld $\mathrm{G}$. An experimental investigation on the evaporation characteristics of a two-component fuel in diesel-like sprays. SAE Int $J$ Engines 2011; 4(1): 800-812 (No. 2011-01-0688).

26. Williams FA. Recent advances in theoretical descriptions of turbulent diffusion flames. In: Murthy SNB (ed.) Turbulent mixing in nonreactive and reactive flows. New York: Plenum Press, 1975, pp.189-208.

27. Peters N. Local quenching of diffusion flamelets and non-premixed turbulent combustion. In: Spring meeting, Irvine, CA, 21-22 April 1980, paper no. WS 80-4. Western States Section of the Combustion Institute. USA: Mechanical and Aerospace Engineering Department, University of California.

28. Peters N. Laminar diffusion flamelet models in nonpremixed turbulent combustion. Prog Energ Combust 1984; 10: 319-339.

29. Peters N. Turbulent combustion. Cambridge: Cambridge University Press, 2000.

30. Pitsch H. Unsteady flamelet modeling of differential diffusion in turbulent jet diffusion flames. Combust Flame 2000; 123: 358-374.

31. Girimaji SS. On the modelling of scalar diffusion in isotropic turbulence. Phys Fluids A: Fluid 1992; 4: 2529 2537.

32. Adolph D, Busch H, Pischinger S, Kolbeck A, Lamping $\mathrm{M}$ and Körfer T. Modernes dieselbrennverfahren. MTZ: Motor Z 2008; 69: 42-50.

33. Lamping M, Kolbeck A, Körfer T, Adolph D, Busch H, Pischinger S. Advanced Diesel Combustion Method demonstrating favourable untreated engine emissions with improved consumption characteristics. MTZ worldwide 2008; 69(1).

34. Lamping M, Janssen A, Kolbeck A, Schernus C, Wohlberg R, Wedowski S, et al. Application of increased 
power density for future diesel engines - a requirement for downsized powertrains. In: Proceedings of the FISITA, Budapest, 30 May-4 June 2010. London: FISTA.

35. Muether M, Lamping M, Kolbeck A, Cracknell R, Rickeard D, Ariztegui J, et al. Advanced combustion for low emissions and high efficiency part 1: impact of engine hardware on HCCI combustion. SAE paper 2008-012405, 2008.

36. Jakob M, Pischinger S, Adomeit $\mathrm{P}$ and Kolbeck A. Glow-plug ignition of ethanol fuels under diesel engine conditions. SAE paper 2011-01-1391, 2011.

37. Fischer SL, Dryer FL and Curran HJ. The reaction kinetics of dimethyl ether. I: high-temperature pyrolysis and oxidation in flow reactors. Int J Chem Kinet 2000; 32: 713-740.

38. Curran HJ, Fischer SL and Dryer FL. The reaction kinetics of dimethyl ether. II: low-temperature and oxidation in flow reactors. Int $J$ Chem Kinet 2000; 32: 741-759.

39. Kaiser EW, Wallington TJ, Hurley MD, Platz J, Curran HJ, Pitz WJ, et al. Experimental and modeling study of premixed atmospheric-pressure dimethyl ether-air flames. J Phys Chem A 2000; 104(35): 8194-8206.

40. Pepiot-Desjardins $\mathrm{P}$ and Pitsch H. An efficient error-propagation-based reduction method for large chemical kinetic mechanisms. Combust Flame 2008; 154: 67-81.

41. Hewson $\mathrm{HC}$ and Bollig M. Reduced mechanisms for $\mathrm{NO}_{\mathrm{x}}$ emissions from hydrocarbon diffusion flames. Symp Combust Proc 1996; 26: 2171-2180.

42. Pepiot P. Automatic strategies to model transportation fuel surrogates. PhD Thesis, Stanford University, Stanford, CA, 2008.
43. Andrae JCG, Brinck T and Kalghatgi GT. HCCI experiments with toluene reference fuels modeled by a semidetailed chemical kinetic model. Combust Flame 2008; 155(4): 696-712.

44. Dooley S, Won SH, Chaos M, Heyne J, Ju Y, Dryer FL, et al. A jet fuel surrogate formulated by real fuel properties. Combust Flame 2010; 157(12): 2333-2339.

45. Farrell J, Cernansky N, Dryer F, Friend DG, Hergart CA, Law CK, et al. Development of an experimental database and kinetic models for surrogate diesel fuels. SAE paper 2007-01-0201, 2007.

46. Krishnasamy A, Reitz R, Willems W and Kurtz E. Surrogate diesel fuel models for low temperature combustion. SAE paper 2013-01-1092, 2013.

47. Pitz W, Cernansky N, Dryer F, Egolfopoulos FN, Farrell JT, Friend DG, et al. Development of an experimental database and chemical kinetic models for surrogate gasoline fuels. SAE paper 2007-01-0175, 2007.

48. Dooley S, Won SH, Heyne J, Farouk TI, Ju Y, Dryer FL, et al. The experimental evaluation of a methodology for surrogate fuel formulation to emulate gas phase combustion kinetic phenomena. Combust Flame 2012; 159(4): 1444-1466.

49. Pitsch H. Entwicklung eines Programmpaketes zur Berechnung eindimensionaler Flammen am Beispiel einer Gegenstromdiffusionsflamme. Master's Thesis, RWTH Aachen University, Aachen, 1993.

50. Musculus MPB, Lachaux T, Pickett LM and Idicheria CA. End-of-injection over-mixing and unburned hydrocarbon emissions in low-temperature-combustion diesel engines. SAE paper 2007-01-0907, 2007. 